\title{
حول ضرورة حماية المستهلك من سوء استخدام الإشهار التجاري
}

\author{
On the need to protect consumers from the misuse of commercial \\ advertising \\ تاريخ الاستلام :2019/06/14 ؛ تاريخ القبول : 2019/06/16
}

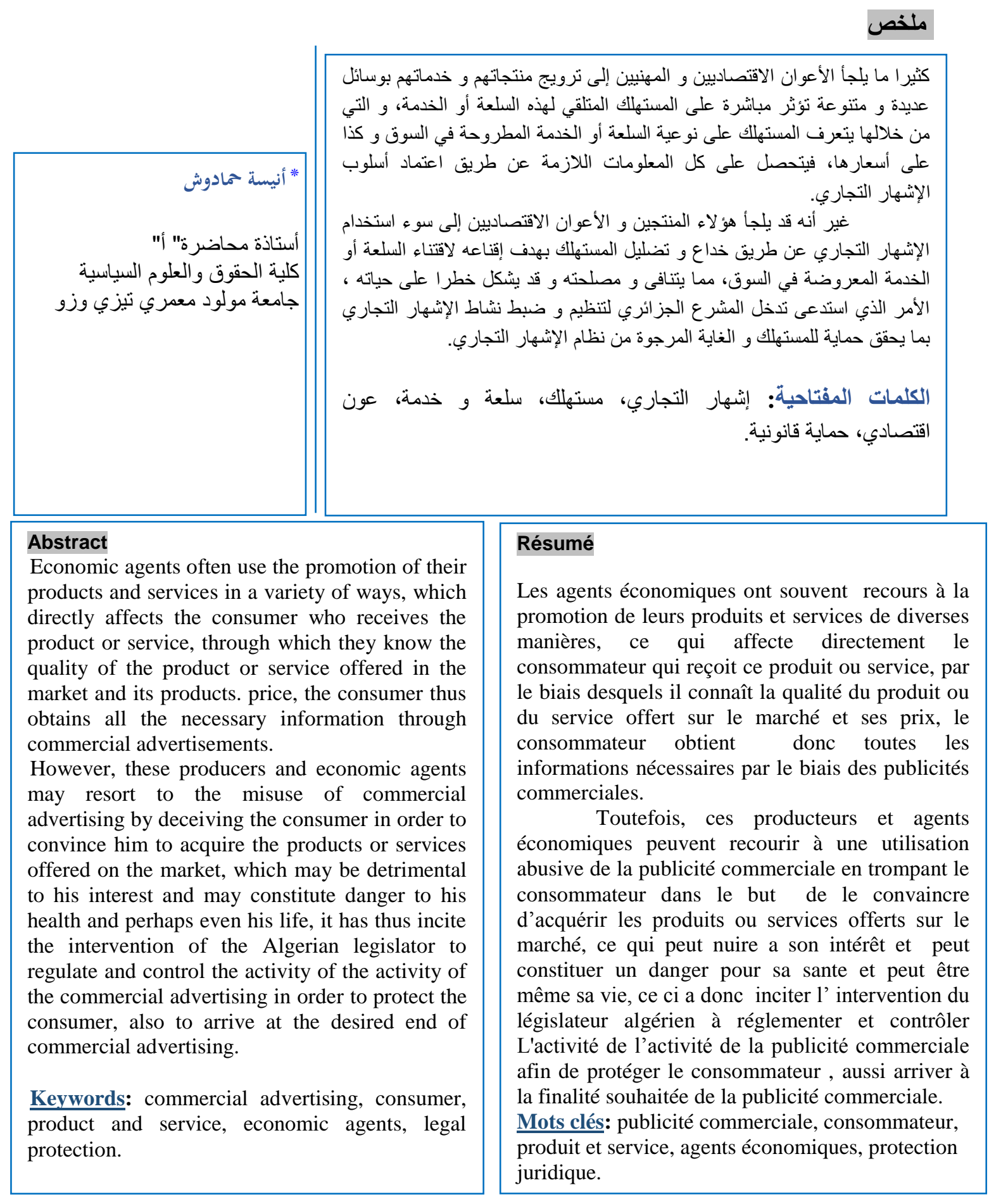

* Corresponding author, e-mail: hamadoucheanissa64@gmail.com 
يعد الإشهار التجاري من الأنشطة الاتصالية التي ترتكز عليها أية مؤسسة اقتصادية في

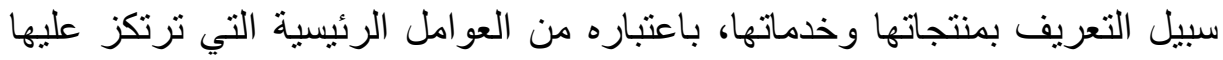

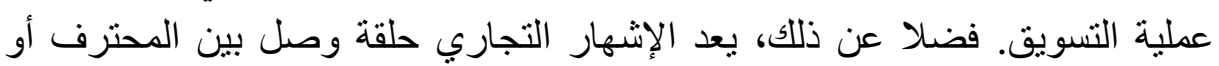

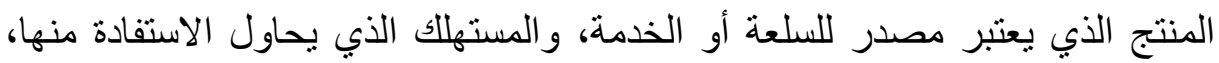
بهدف تلبية رغبة الاستهلاك الشخصي أو العائلي.

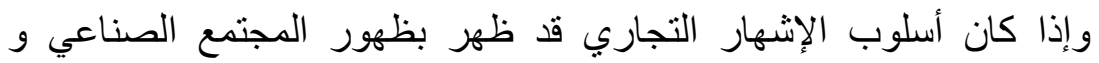

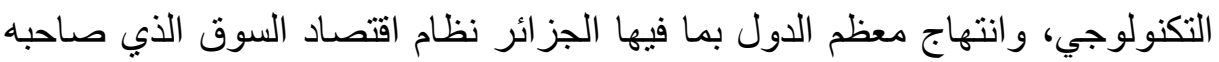

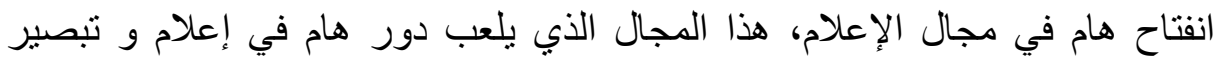

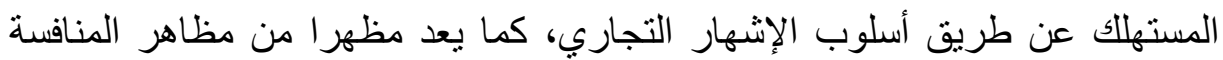

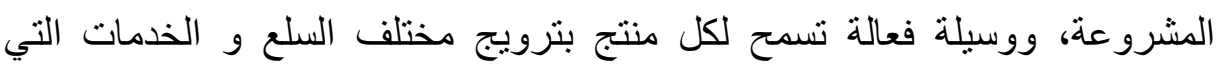
يعرضها للمستهلكين. مع ذلك، قد يشكل نشاط الإشهار التجاري وسيلة للتحايل و الخداع، بسبب التأثنير السيكولوجي الذي يمارسه على نفسية المستهلك و على حقه في الحصول على كلى كل

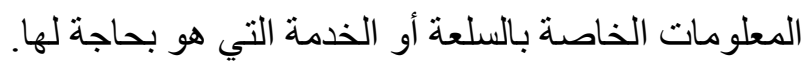

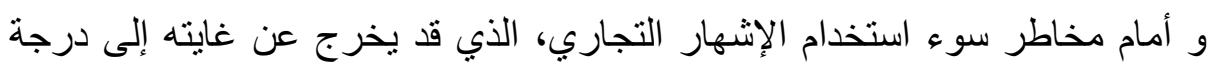

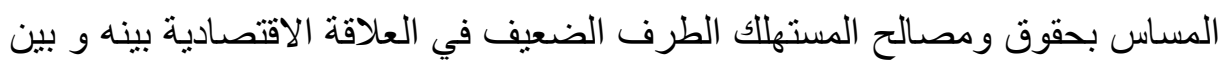

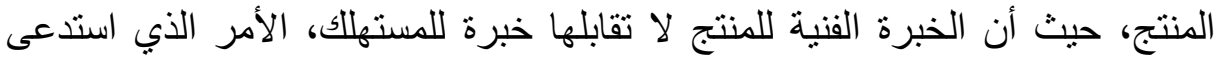

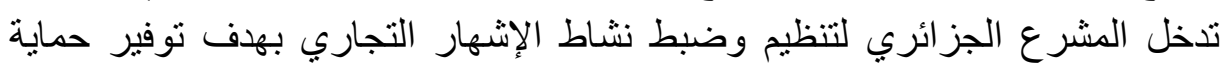

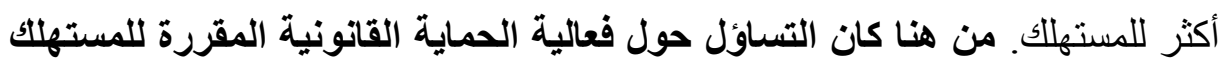
من سوء استخدام الإشهار التجاري. وبهدف الإجابة على هذه الإشكالية، ارتأينا معالجة موضوع الإثهار هذه الدراسة من خلال

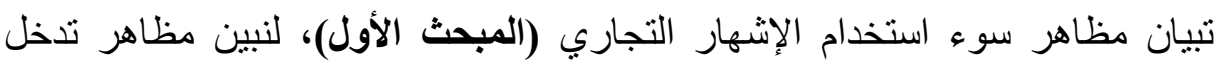

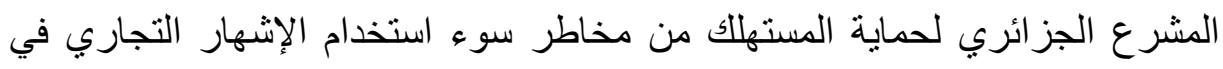
مجال تسويق المنتجات و الخدمات (المبحث الثاني).

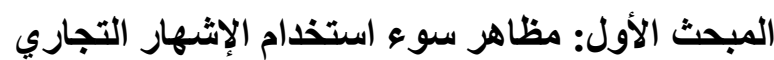
إن التنافس من أجل الحصول على أكبر حصة من السوق، و و تصريف الإنهارئ أكبر قدر مدكن

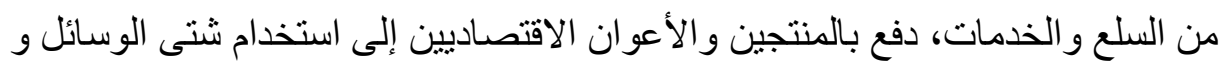

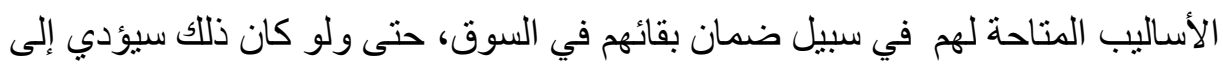
الإضر ار بالمستهرلك. بذلك، سيتحول الإشهار التجاري من أداة لترويج السلع و الخدمات و تحفيز النافسة بين

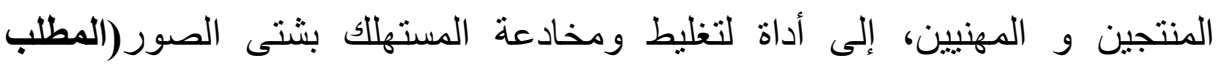

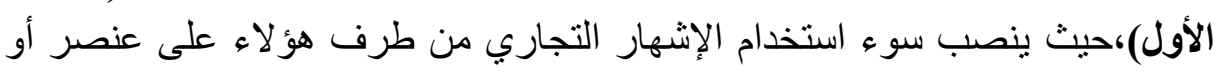
أكثر من العناصر المكونة لنشاط الإشهار التجاري(المطلب الثاني).

المطلب الأول: صور سوء استخدام الإشهار التجاري يمثل الإشهار التجاري الوسيلة الأساسية التي يتلقى من خلالها الإها المستهلك على كل 
المعلومات الضرورية الخاصة بالمنتوج أو الخدمة، و التي يعتمد عليها في اتخاذ قراره

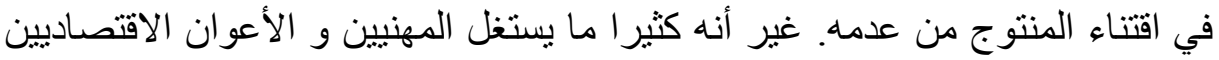

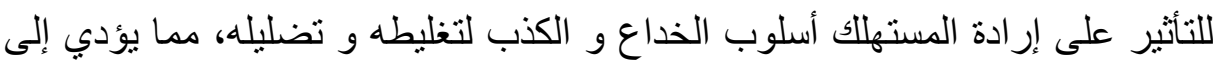

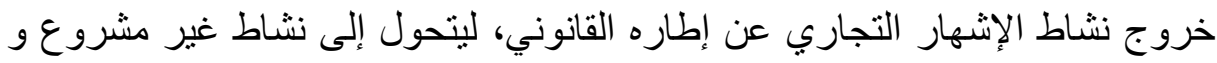

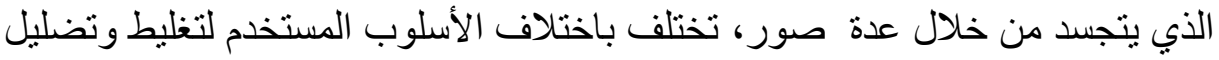

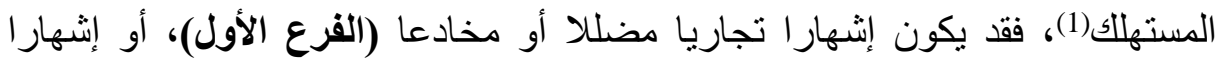
تجاري كاذبا(الفرع الثاني)، كما قد يكون إثهار ا تجاريا مقارنا (الفرع الثالث).

الفرع الأول: الإشهار التجاري المظلل أو المخادع

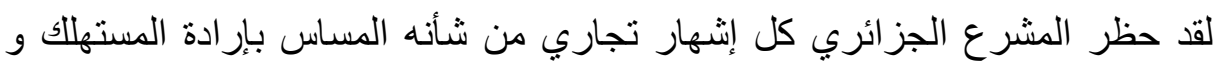
يتسبب في تغليطه و تضليله. ذلك أن الإشهار التجاري الكاذب، هو كل إثهار يتضدن عروضا خاطئة و إدعاءات مخالفة للحقيقة. و إذا كان الفقه يعرف الإشهار التجاري على أنه: " كل إخبار أو إعلام تجاري القصد

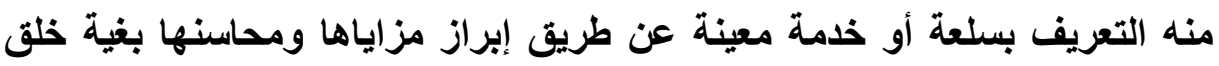

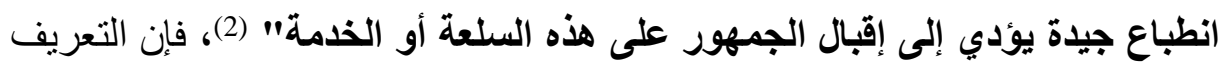

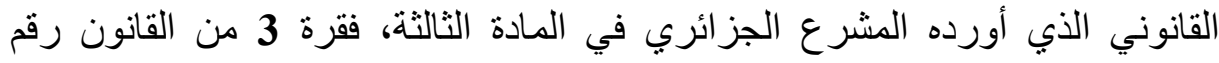
04 02 الذي يحدد القو اعد المطبقة على الممارسات التجارية يعرف الإشهار بأنها 3 " ... كل إعلان يهذف إلى ترويج و بيع السلع أو الخدمات مهما كان المكان أو وسائل الاتصال المستعملة"(3). و أما المادة 1/3 من المرسوم التنفيذي رقم 13_378 الذي يحدد الثروط والكيفيات

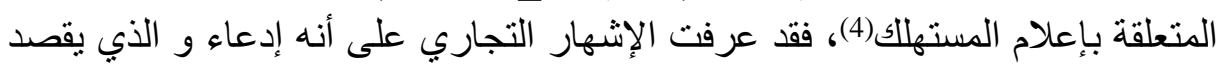

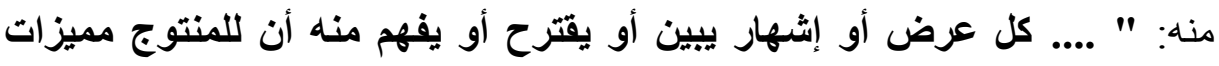

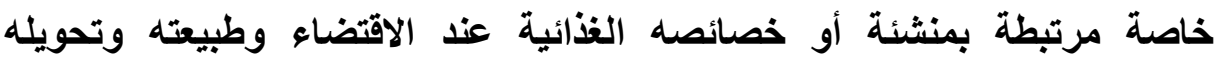

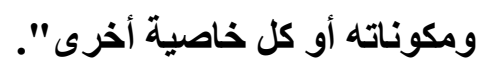
أما عن الإشهار التجاري المظلل أو المخادع (Publicité trompeuse)، فلقد أوند تطرق المشرع الجزائري إلى ذكر صورة لهذا النوع من الإشهار في المادة 28 من قانون رقم

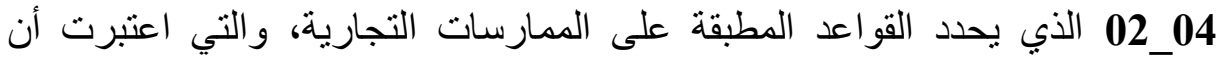
الإشهار التجاري المظلل إثهار ا غير شرعي وممنوع في الحالات التالية:

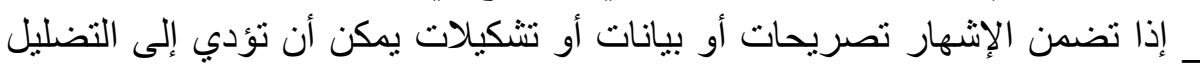

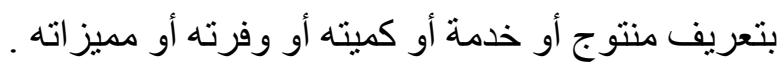

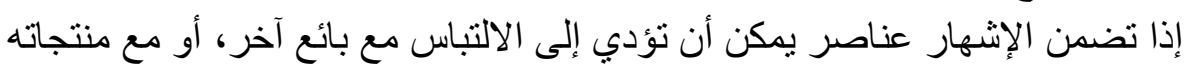

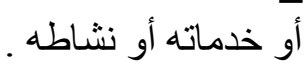

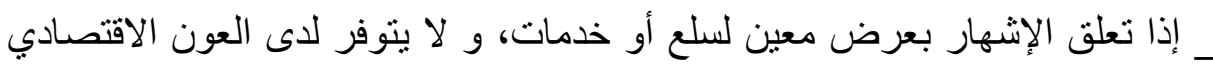

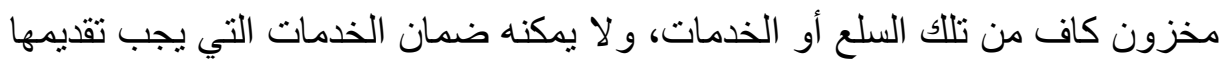
عادة، بالمقارنة مع ضخامة الإشهار (5). و أما القانون رقم 09_03 المتعلق بحماية المستهلك وقمع الغش و6ه، فلقد عرف في المادة 
68 منه الإشهار التجاري المظلل على النحو التالي:" ... كل من يخدع أو يحاول أو يخدع المستهلك بأية وسيلة أو طريقة كانت ....

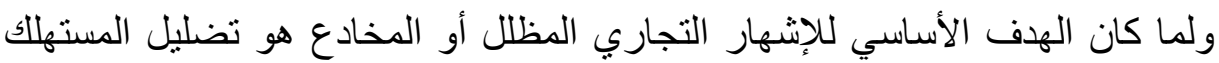

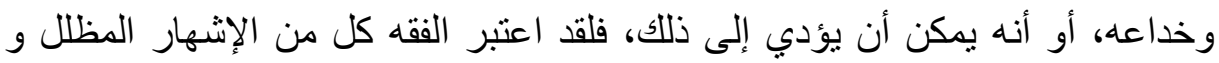

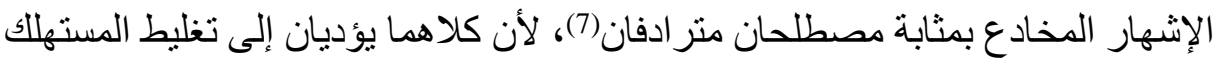

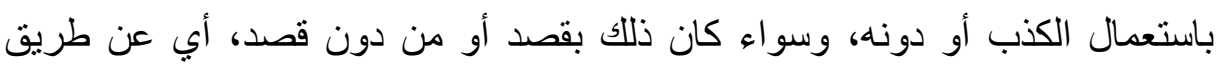

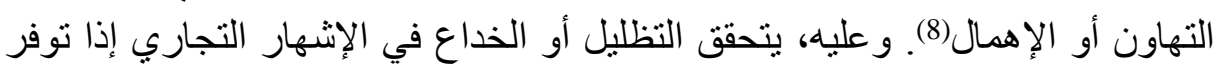
عنصران: - (انهاون العنصر الأول: يكون مادي ويتمثل في وجود الإشهار المظلل مهما كانت وسيلة التعبير عنه، وأن ينصب هذا التظليل على إحدى العناصر التي نصت فت عليها المادة 28 من قانون رقم 04_02، والمادة 68 من القانون رقم 09_03 المتعلق بحماية المستهلك و

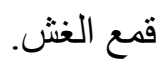
العنصر الثاني: يتمثل في الجانب المعنوي للإشهار المظلل، و الذي يقصد به نوفر

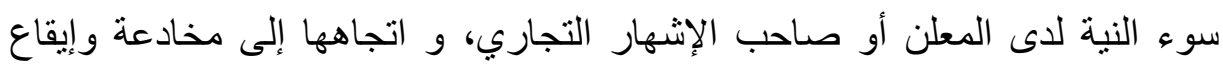

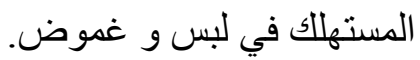

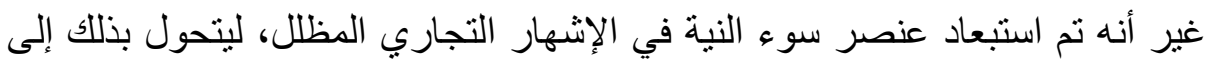
جريمة مادية(9)، على أساس أن القانون يجرم الفعل المادي. ومن ثم يستوي فئوي أن يكون

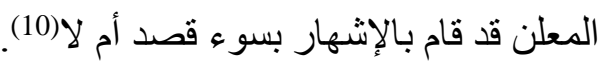

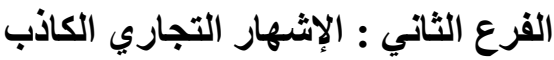
يقصد بالكذب، إخبار عن شيء بخلاف ما هو في الحقيقة أو الو اقع، سواء كان ذلك عن قصد أم نتيجة خطأ(11). ويعتبر الإشهار التجاري إثهارا كاذبا (Publicité mensongère) حسب وجهة نظر الفقه:" يكون الإشهار كاذبا منذ اللحظة التي لا تتطابق فيه الرسالة الإعلانية

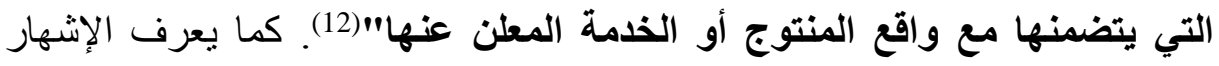

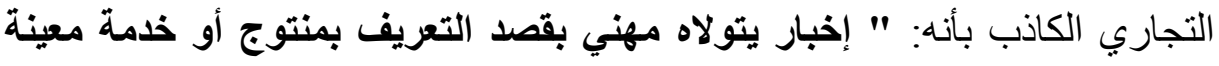

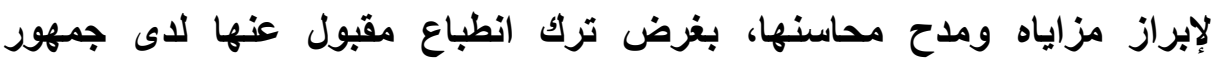

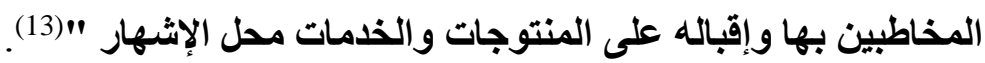

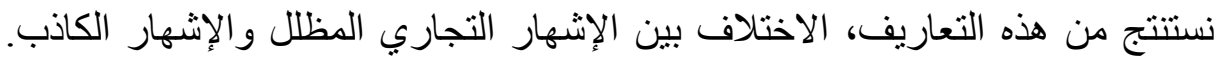

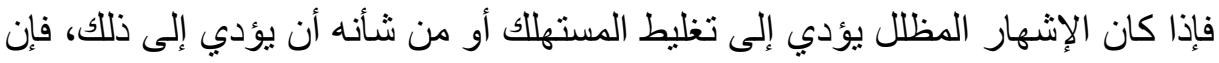
الإشهار الكاذب يتمثل في وجود كذب يؤدي إلى غش المستهارئلك، ومن ثمة فإن الإشهار

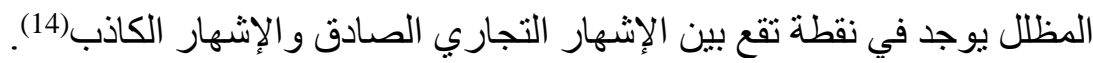

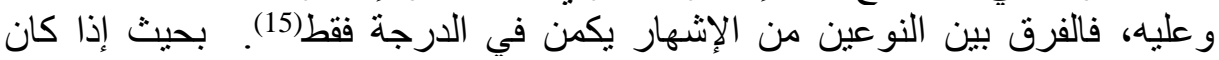

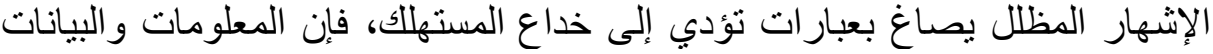

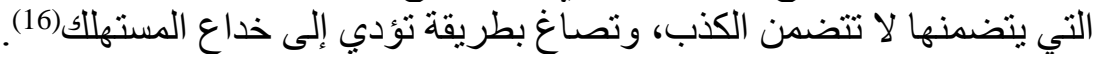

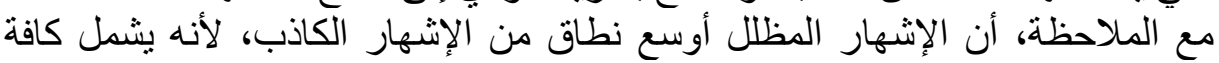
صور الإشهار الكاذب(17)، ولكن العكس غير العن صحيح. 
الفرع الثالث: الإشهار التجاري المقارن

لا يقتصر الإشهار التجاري على خداع وتظليل المارن المستهلك، بل قد يمتد إلى المساس و

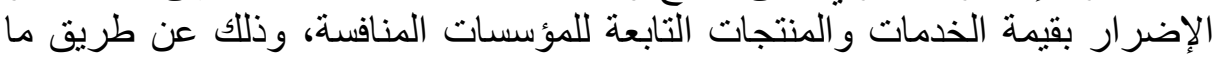

يسمى بالإشهار المقارن.(Publicité comparative)

يتجسد الإشهار التجاري المقارن في قيام المعلن بإظهار و إبراز محاسن و و مزايا سلعة التحان

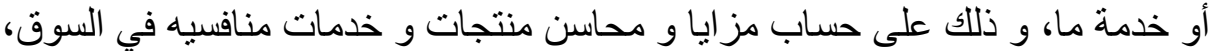

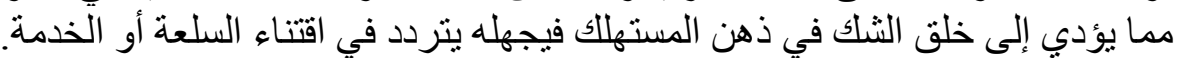

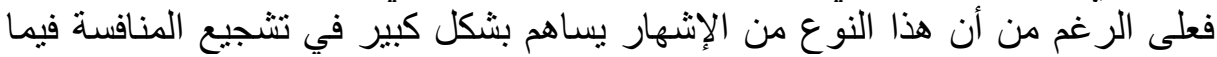

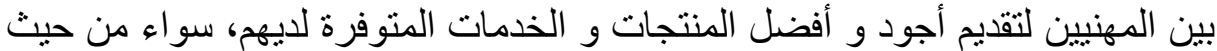

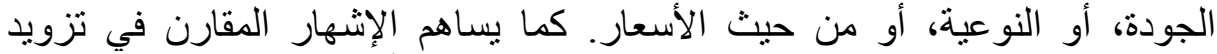

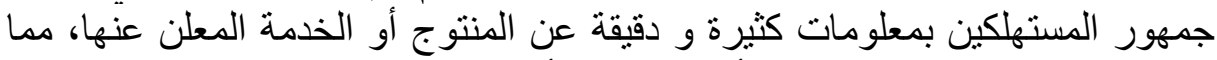

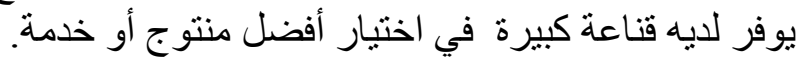

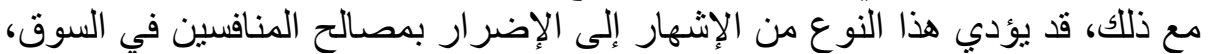

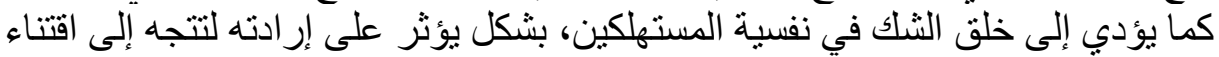

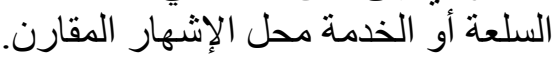
يلعب هذا النوع من الإشهار التجاري دورا هاما في تشويه منتجات وخدمات الأعوان

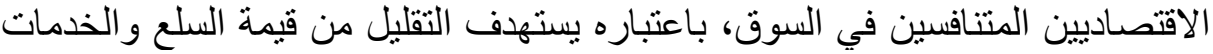

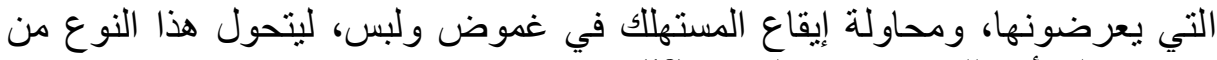

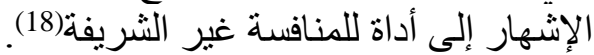

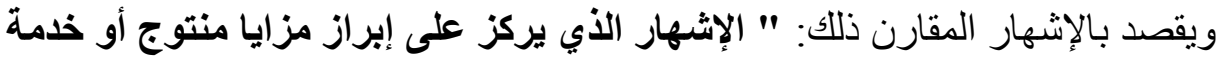

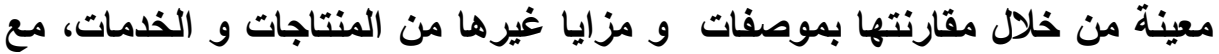

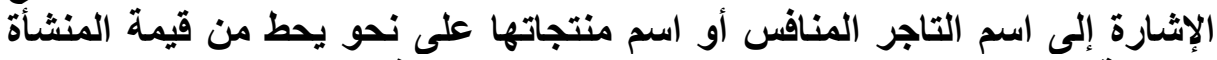

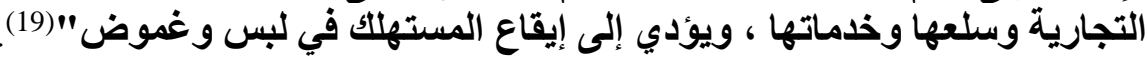

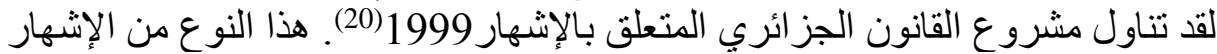

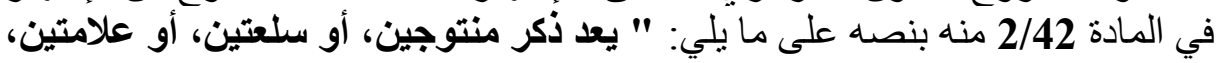

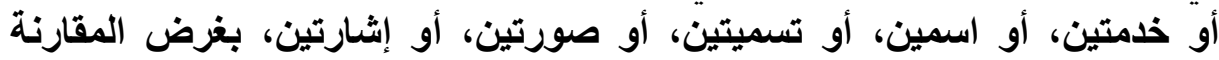

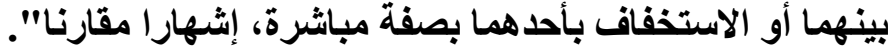

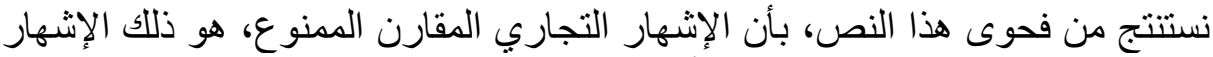

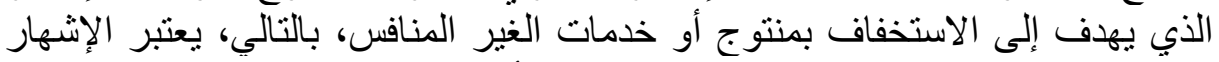
المقارن ممنو عا بموجب نص المادة 42 المذكورة أعلاه مهما كان شكله.

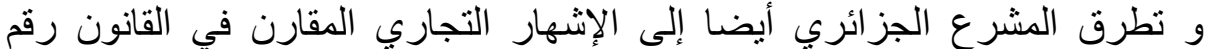

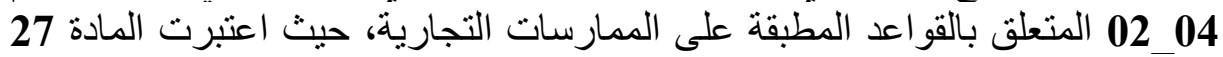

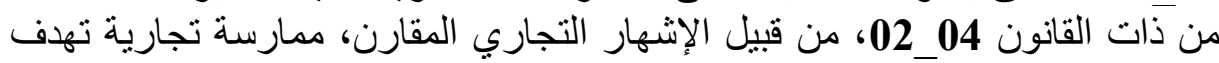

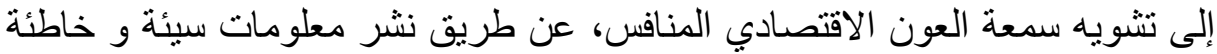

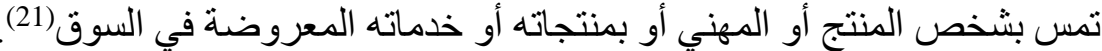

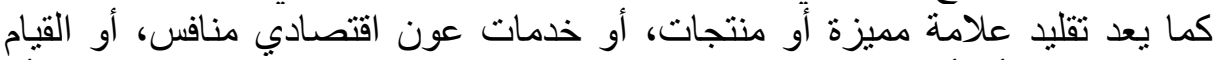

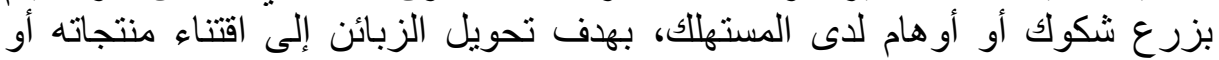
خدماته(22)، من قبيل الإشهار التجاري المقارن، لأن الهدف منه إيقاع المستهلك ضحية التهات

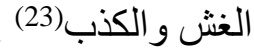
و حظر المشرع الجزائري الأعوان الاقتصاديين الأضرار بمنافسيهم، وذلك عن طريق الكاريق

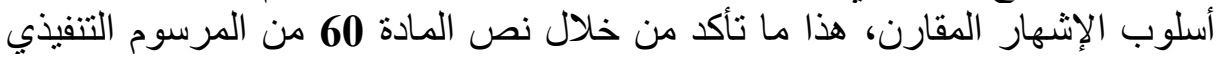

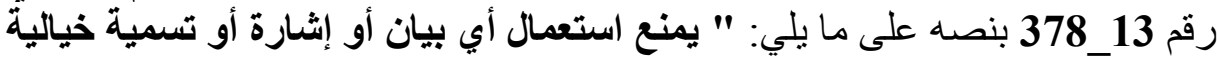

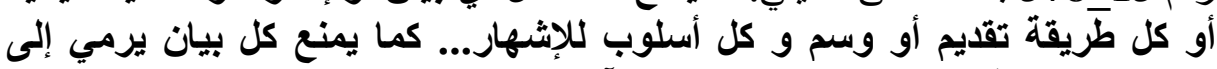

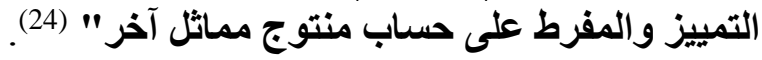


المطلب الثاني: محل التظليل والخداع في الإشهار التجاري

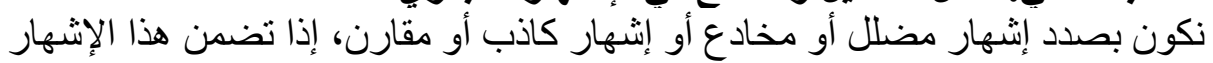

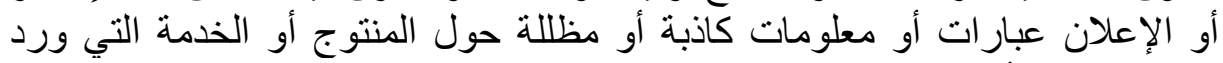

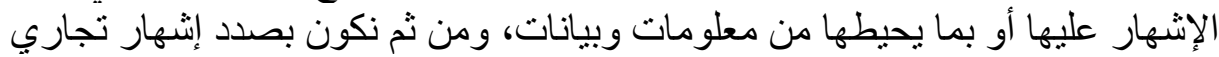

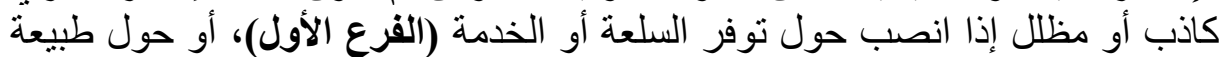

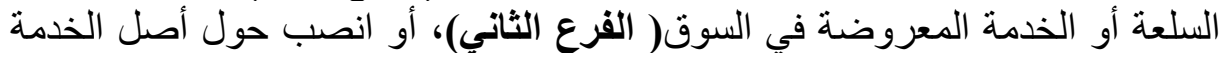

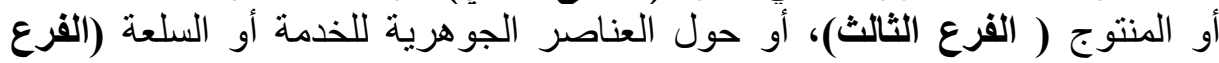
الر الرع).

الفرع الأول: الإشهار المظلل أو الكاذب حول توفر السلعة أو الخدمة

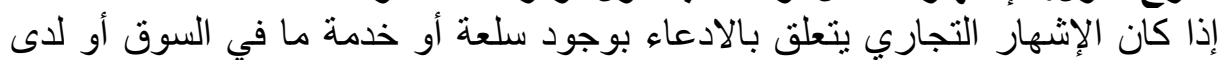

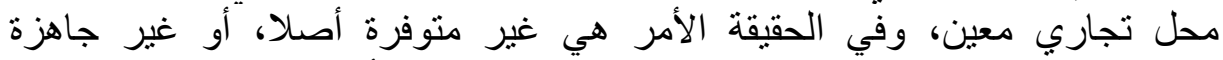

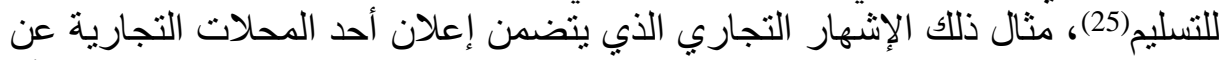

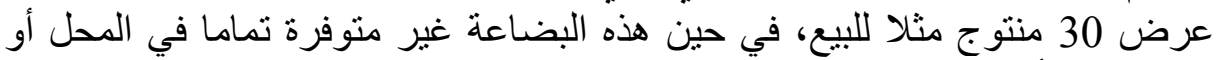

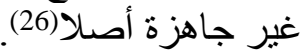

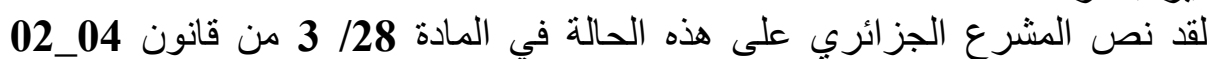

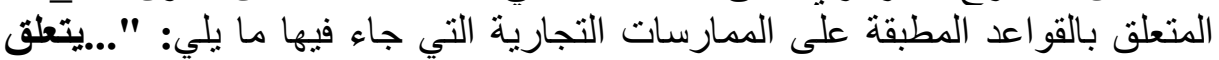

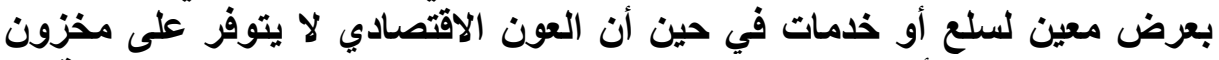

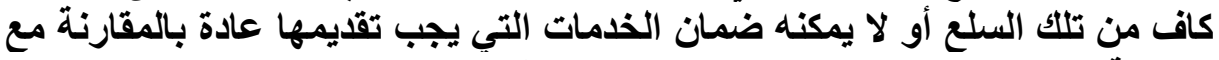

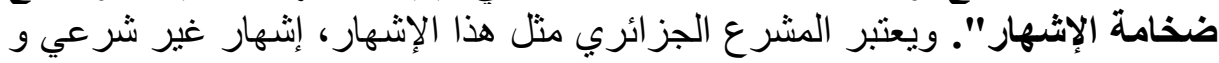
منوع، و يتابع صاحبه قانونا.

الفرع الثاني: الإشهار المظلل أو الكاذب حول طبيعة السلعة أو الخدمة المعروضة

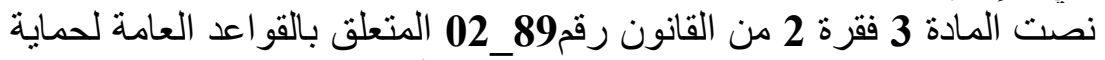

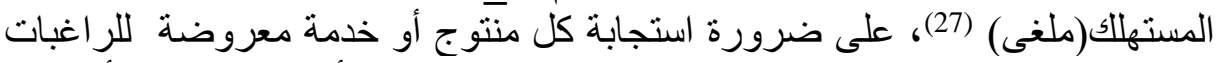

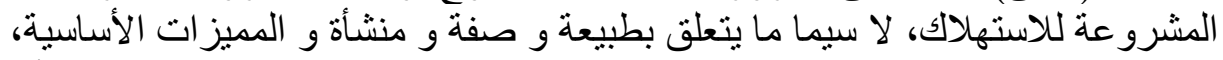

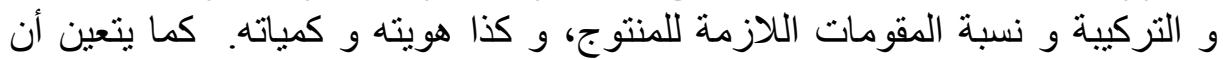

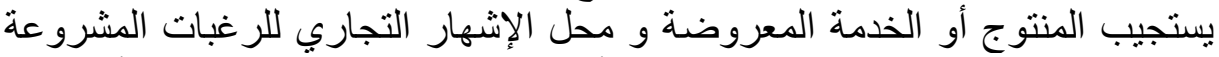

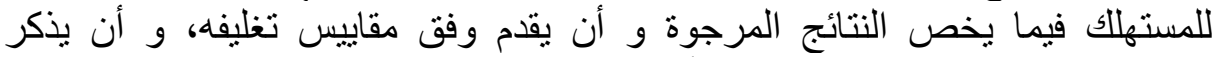

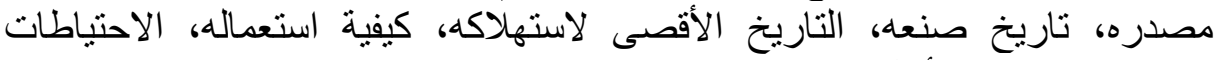

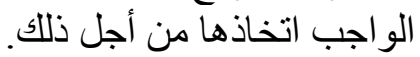
وعليه، يعد من قبيل الإشهار المظلل والكاذ ذاذب، ذلك الإشهار الذي يتضمن بيانات أو

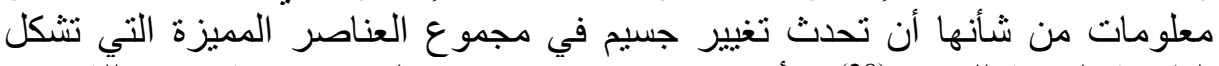

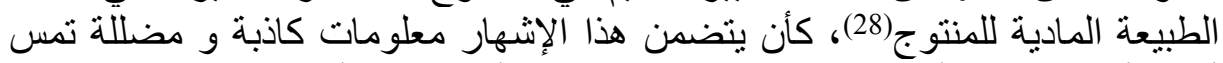

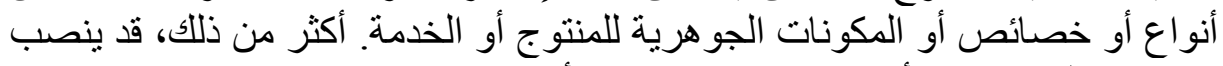

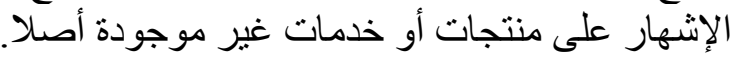

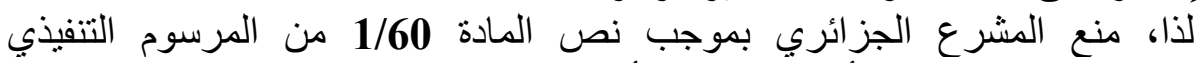

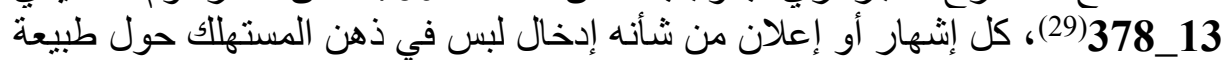

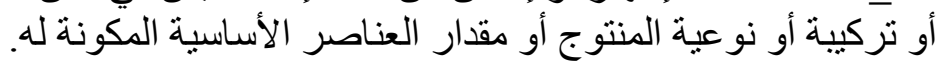

الفرع الثالث: الإثهار الكاذب والمظل حول أصل الخدمة أو المنتوج

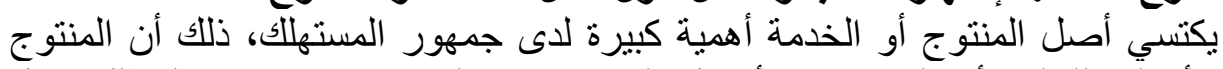

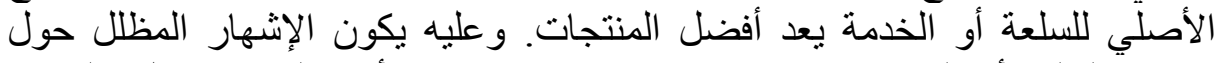

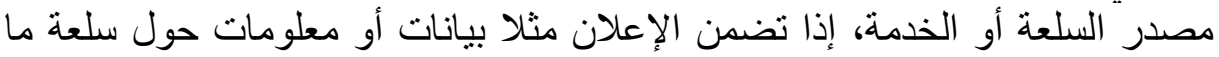




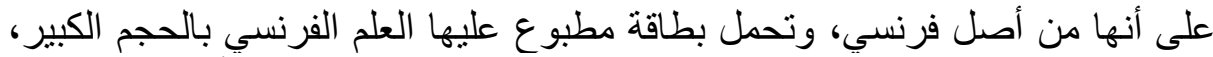

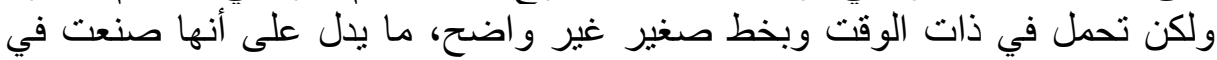
الصين(30).

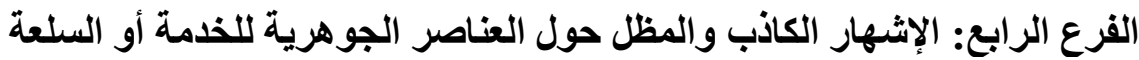

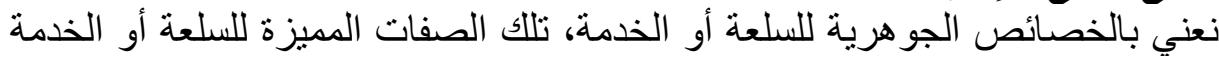

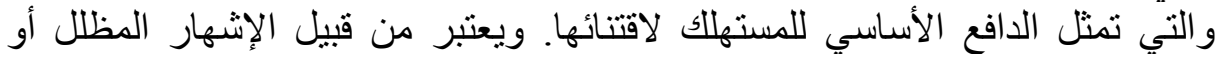

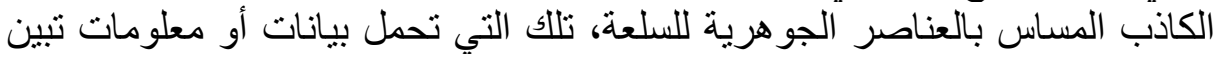

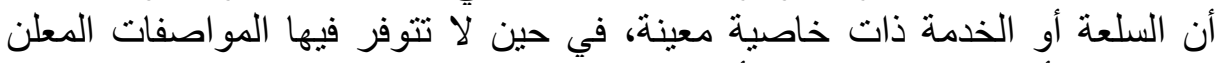

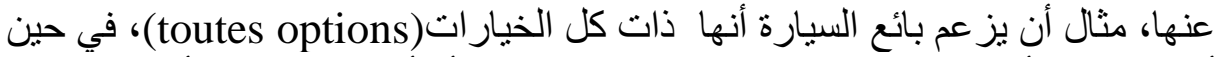

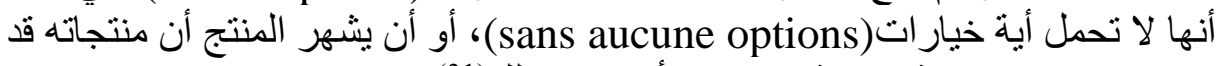

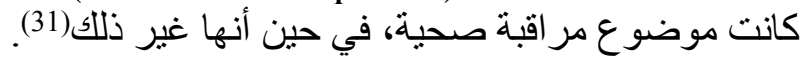

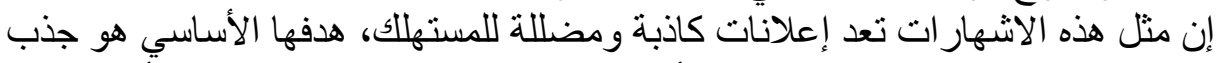

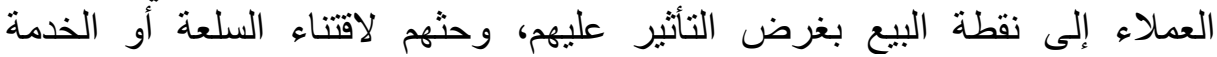

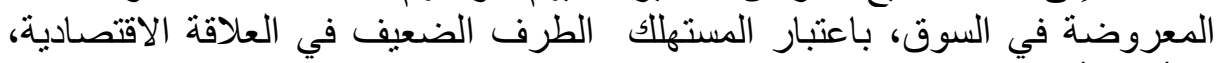
والأكثر تأثير في الإشهار الكاذب واعنار المخادع.

المبحث الثاني: مظاهر حماية المستهلك من سوء استخدام الإشهار التجاري

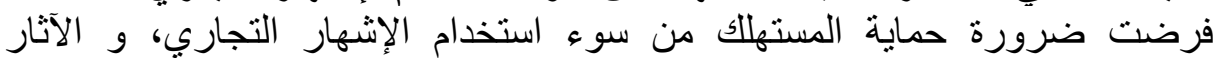

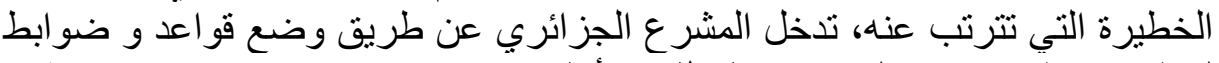

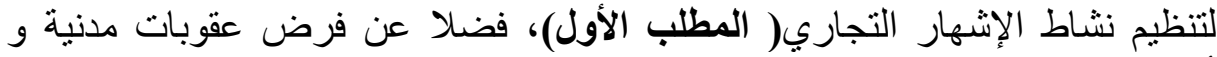

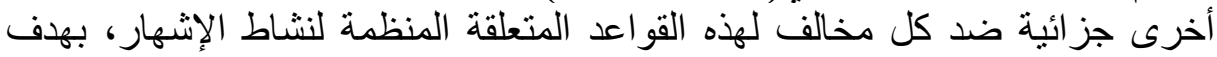
حماية مصلح و حقوق المستهلك فئ المطلب الثاني).

المطلب الأول: القواعد والضوابط القانونية الخاصة بالاشهارات التجارية

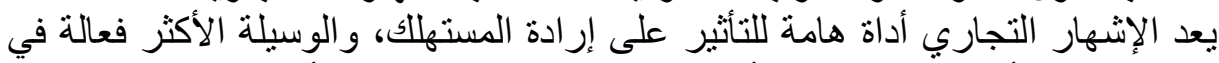

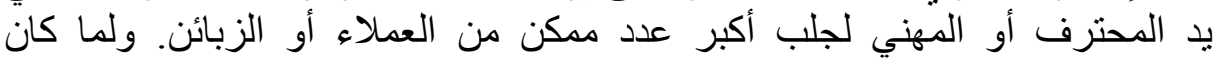

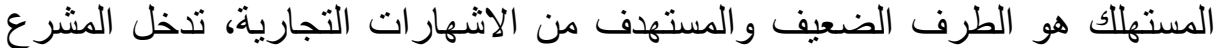

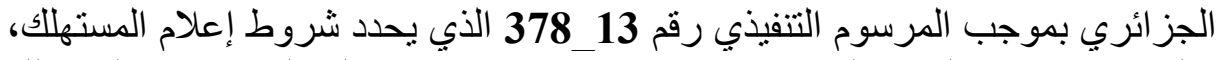

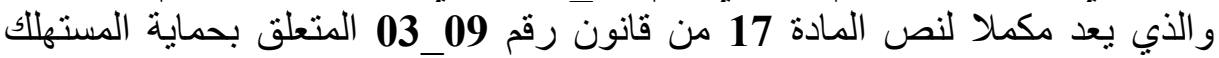

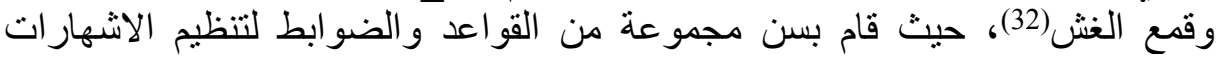

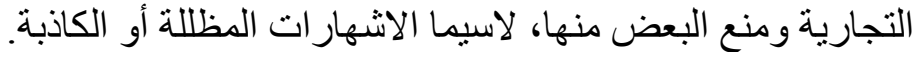

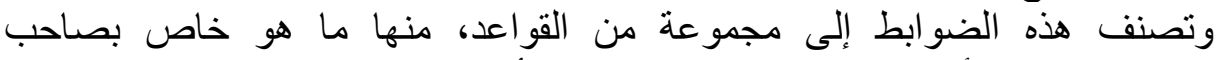

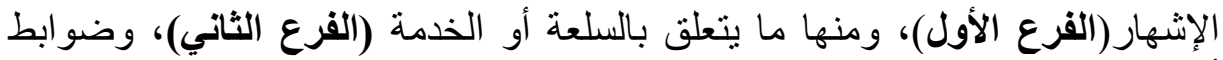

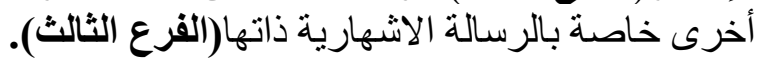

\section{الفرع الأول: الضوابط الخاصة بصاحب الرسالة الاشهارية}

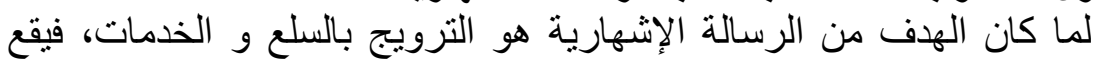

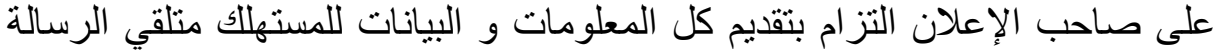

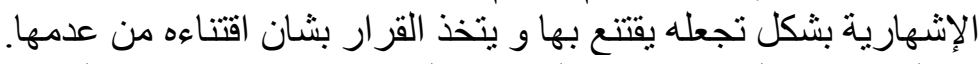

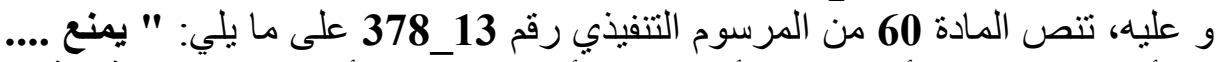

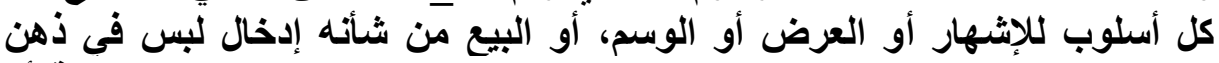

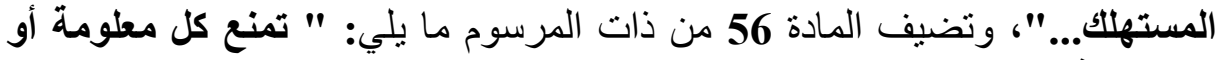

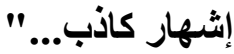

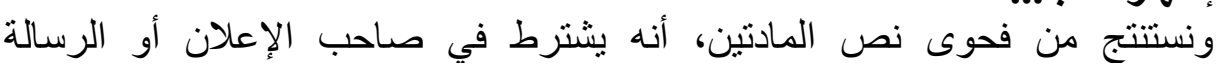
الإشهارية، أن يكون صادقا وأمينا، وأن تكون الرسالة الإشهارية خالية من كل خداع أو الو الئ 
كذب عند تقديمه لمنتوج أو خدمة ما، لتجنب الأضرار بالمستهلك و بمصالحها. بالنتيجة، يلتزم صاحب الرسالة الإشهارية تجنب كل خداع أو كذب ضأب ضد المستهلك، كما

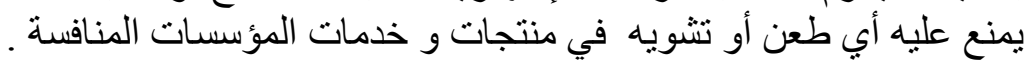

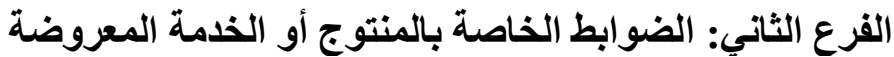

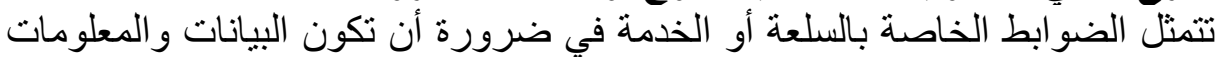

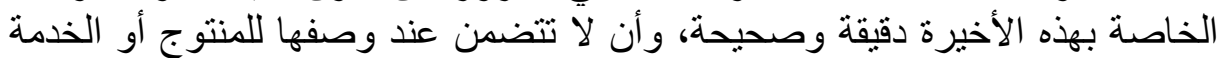

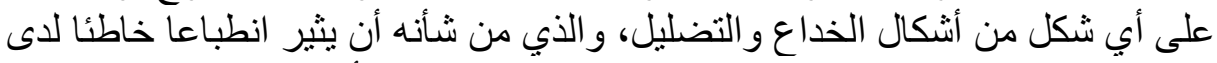

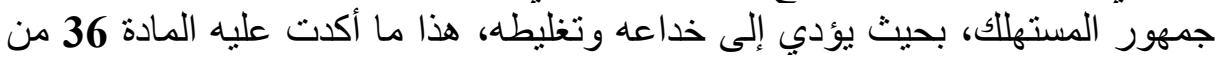
المرسوم التنفيذي رقم 13_ 378 المذكور أعلاه(33).

الفرع الثالث: الضوابط الخاصة بالرسالة الإشهارية

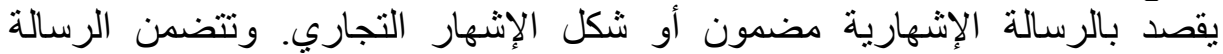

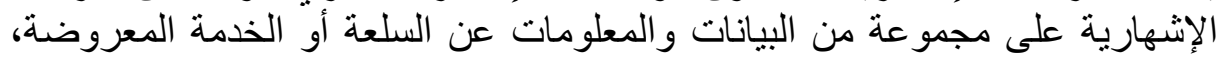

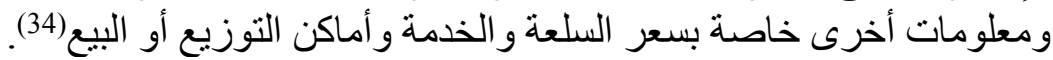

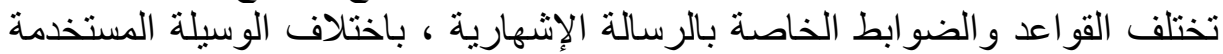

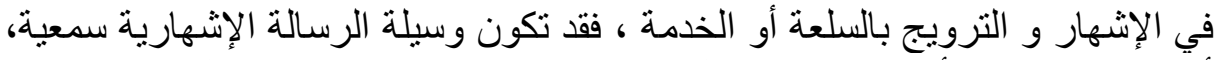

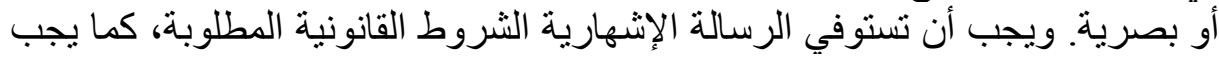

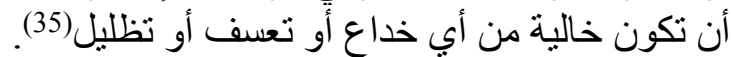

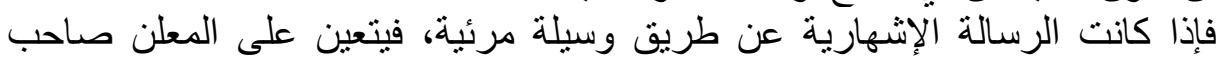

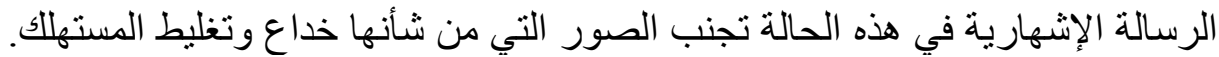

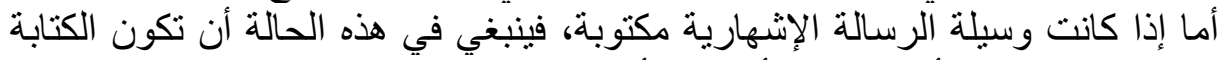

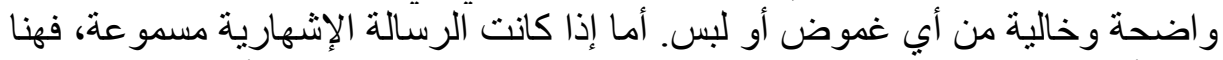

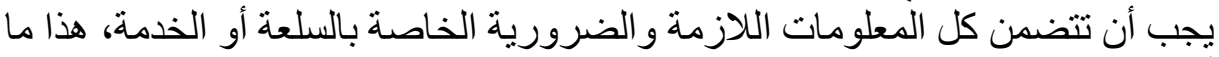

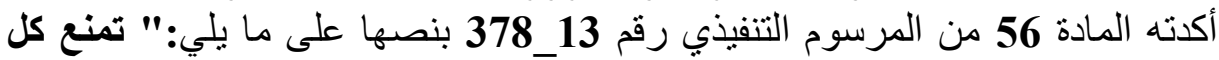

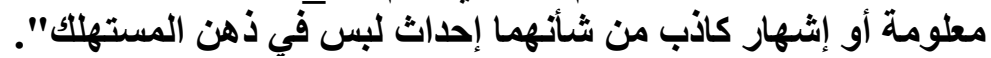

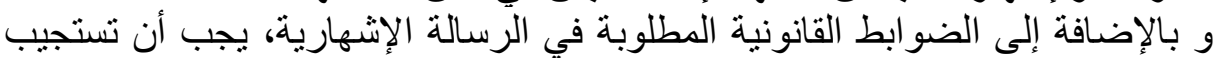

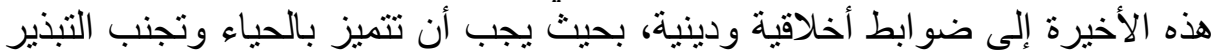

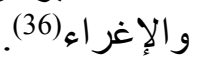

المطلب الثاني: جزاء سوء استخدام الاشهارات التجارية:

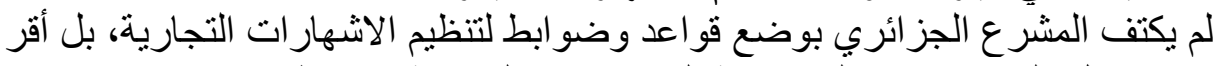

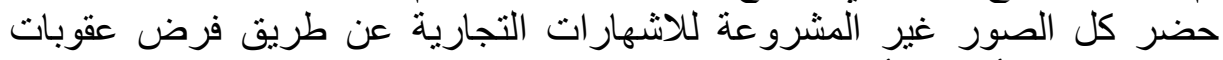

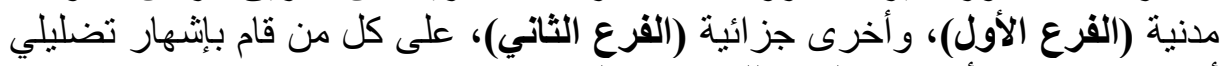
أو كاذب بهدف الأضر ار بالمستهلك و برى بمصالحه.

الفرع الأول: الجزاعات المدنية:

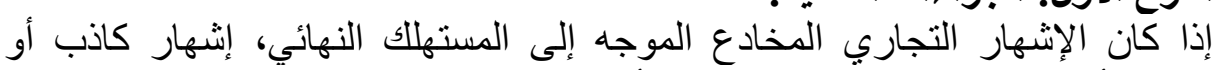

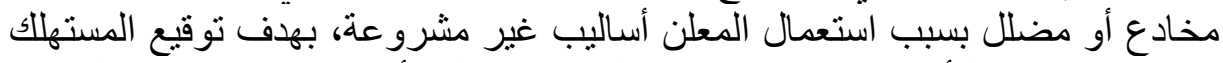

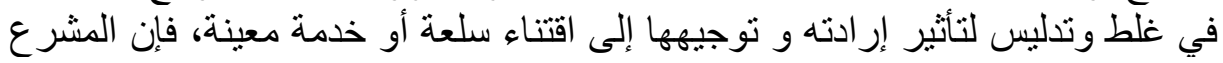

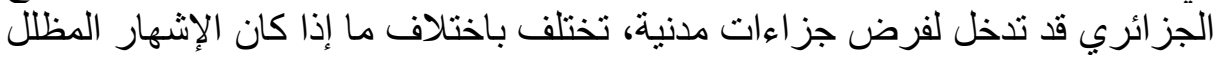

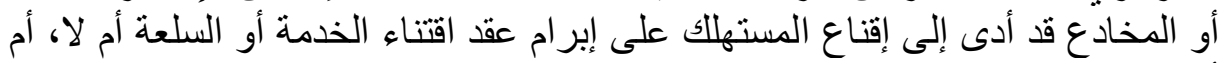
أن الإعلان التجاري يشكل عملا ضار الما بمصالح جمهور المستهلك. 


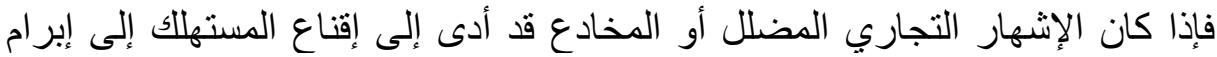

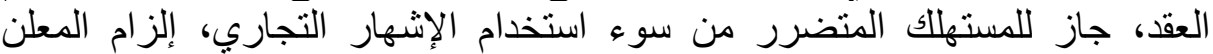

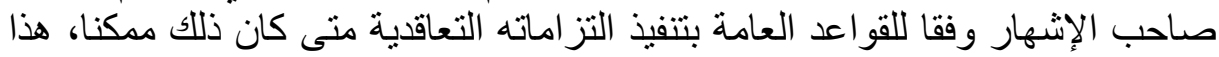

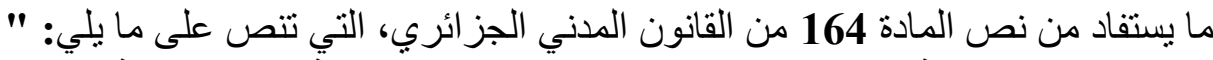
يجبر المدين بعد اعذراه طبقا للمادتين 180 و 181 على تنفيذ التزامه تنفيذا عينيا، متى كان ذاللك ممكنا"(37).

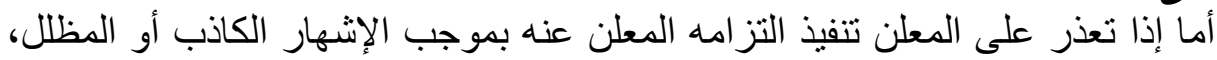

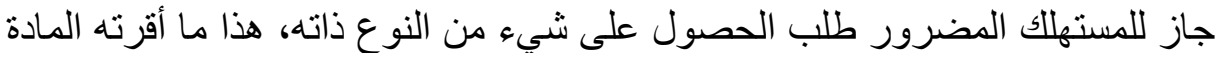

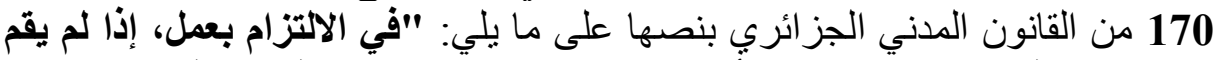

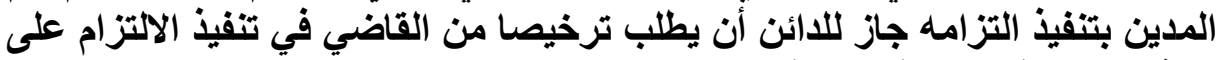
نفقة المدين إذا كان هذا التنفيذ ممكنا".

فضلا عن ذلك، جاز للمستهلك المتضرر من الإشهار المضلل أو المخادع، طلب إبطال

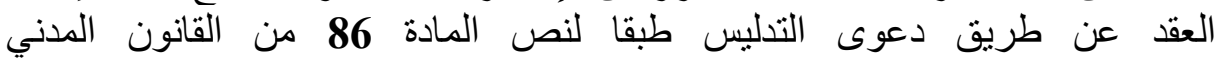

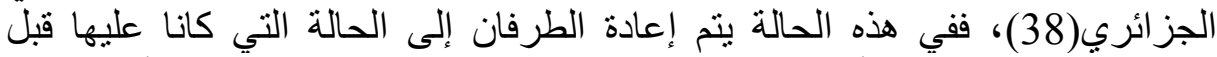

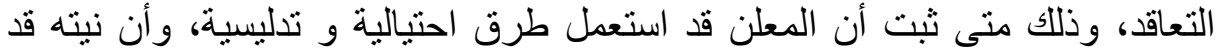

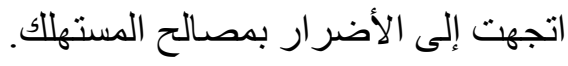

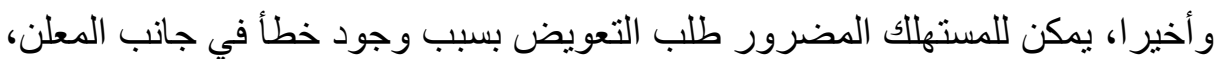

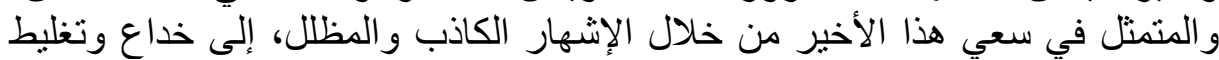

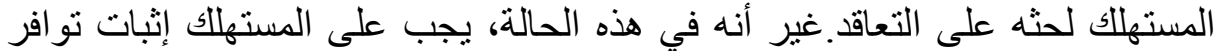

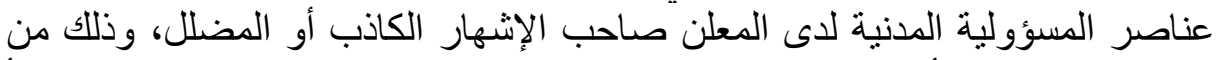

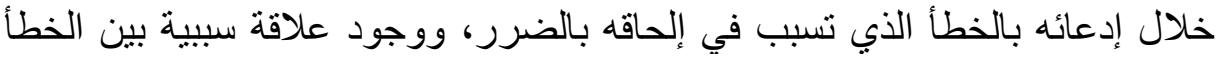

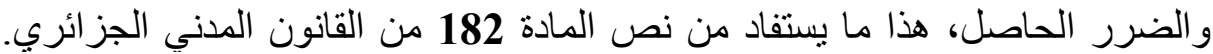

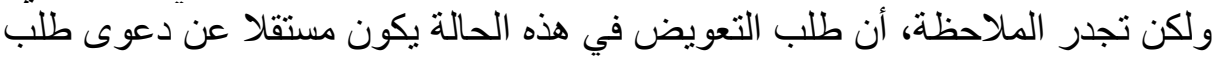
تنفيذ الالتزام أو دعوى التدليس(39).

أما إذا كان سوء استعمال الإشهار التجاري يشكل فعل وفق نص المادة 124 من القانون

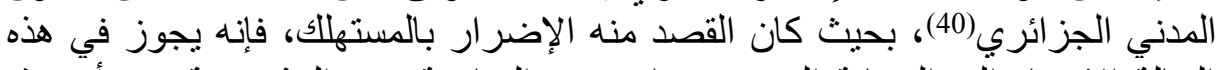

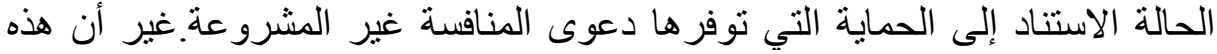

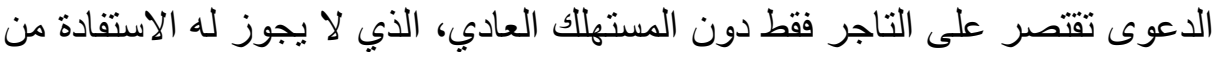

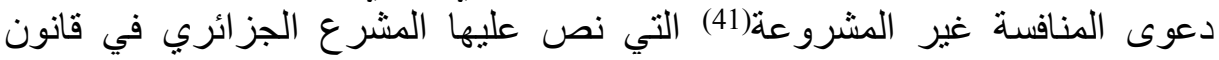
02/04 الخاص بالممارسات التجارية(42).

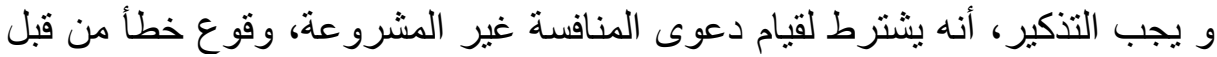

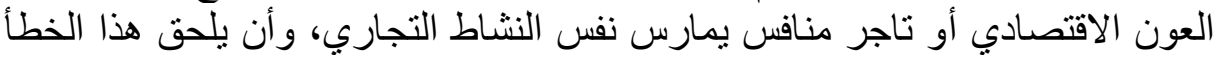

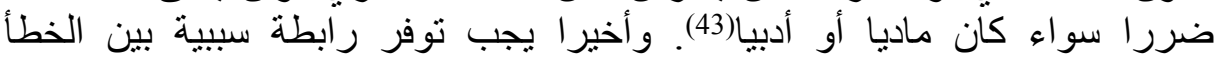

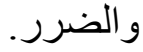

لا"تتحصر الأخطار و والجزانة: الأضرار الناجمة عن سوء استخدام الإشهارات الفرع الثاني: العقوبات الجزائية:

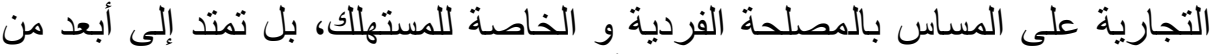

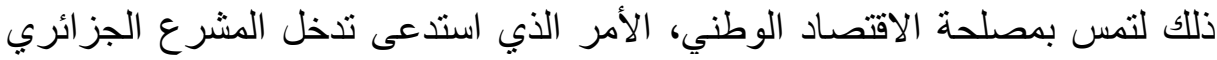

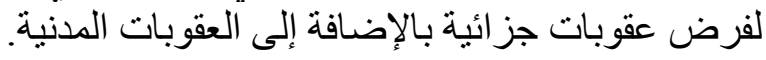
لم يتضمن قانون رقم 03-09 المتعلق بحماية المستهللك وقمع الغش، نص جلاته جزائي خاص 
بالاشهار ات التجارية المضللة والمخادعة، غير أن المادة 68 من هذا القانون، قد أحالت

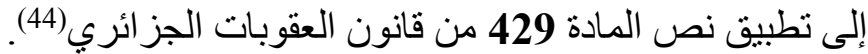

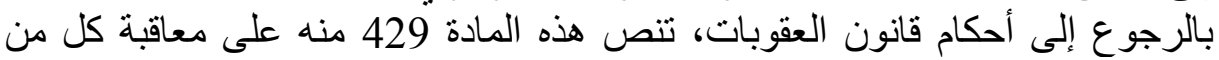

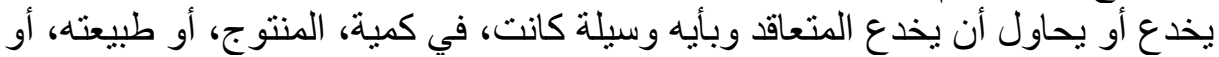

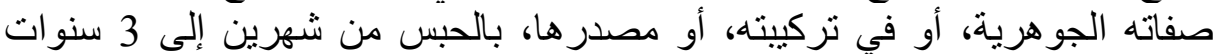

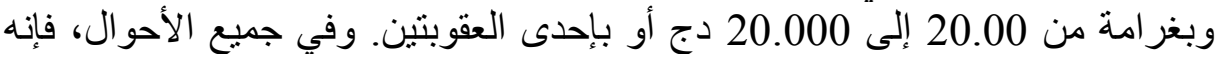

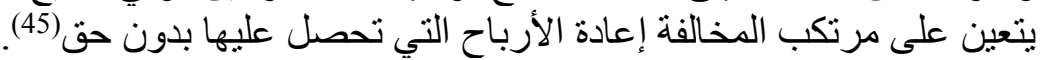

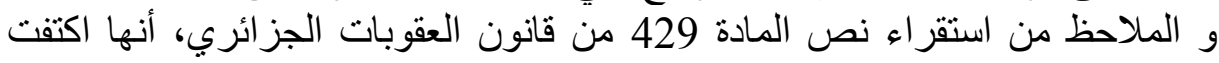

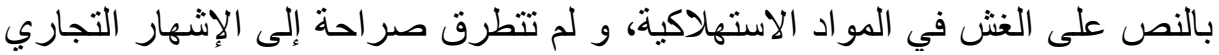

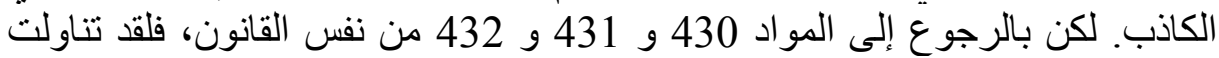

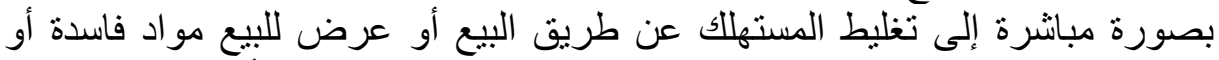

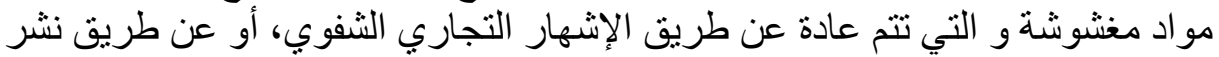

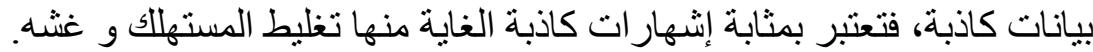

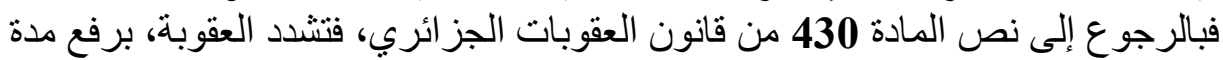

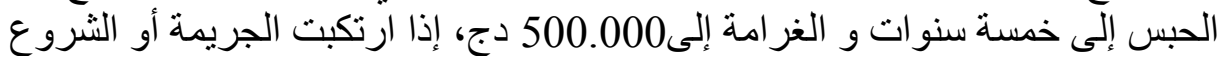

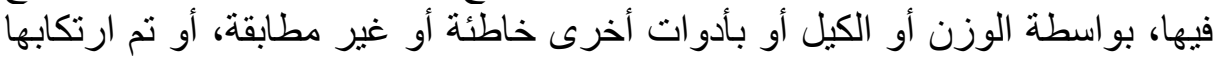

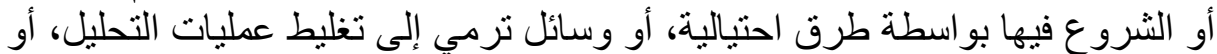

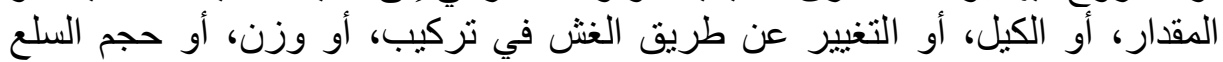

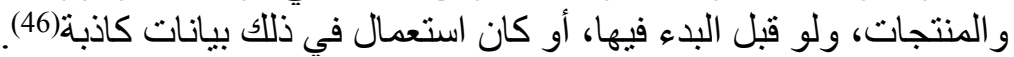

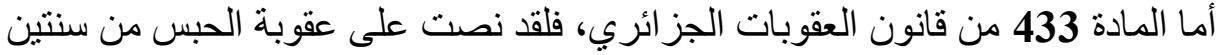

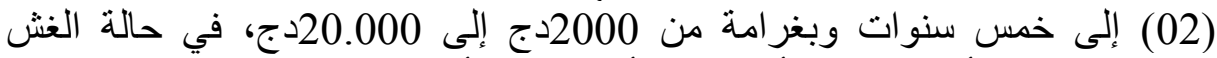

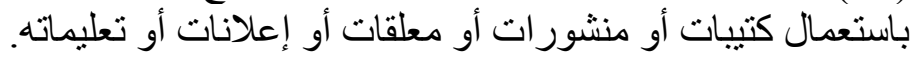

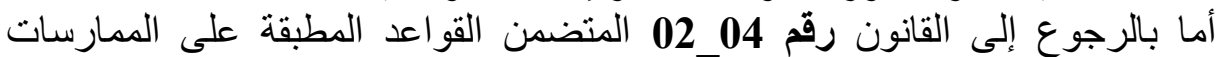

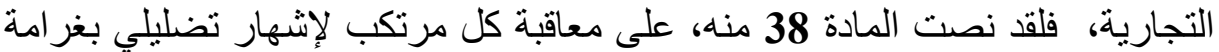

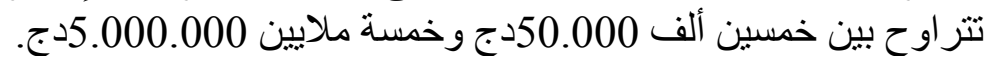

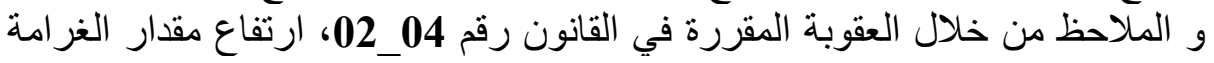

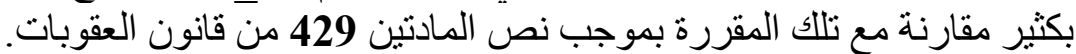

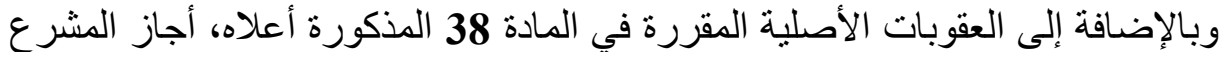

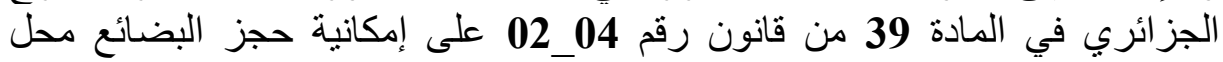

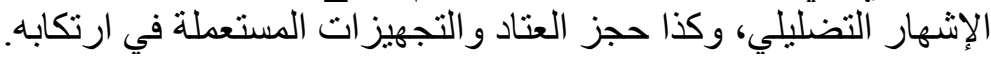

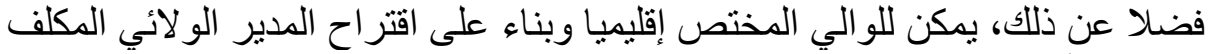

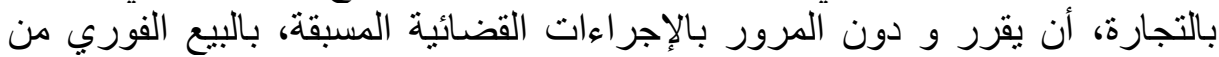

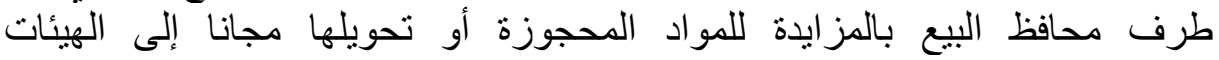

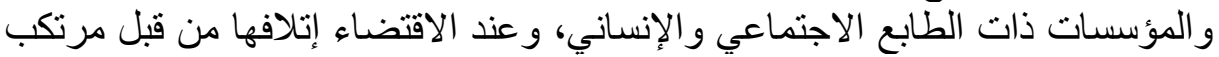

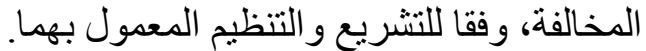

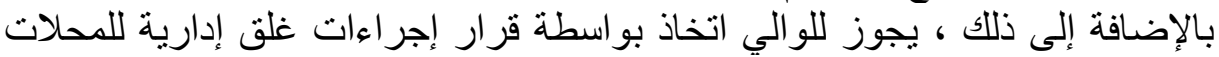

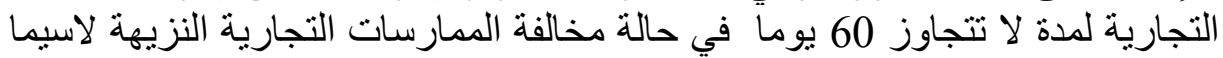

الإشهار التضليلي(47).

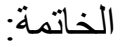

إذا كان الإشهار التجاري وسيلة هامة في يد المؤسسات و الأعوان الاقتصاديين في

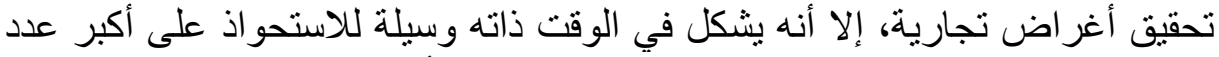

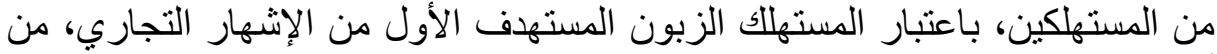
أجل تعريفه بخصائص و مميزات السئع السئ و الخدمات المر اد ترويجها. 


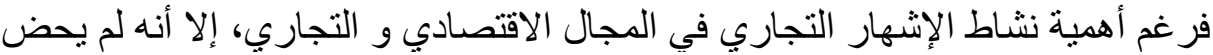

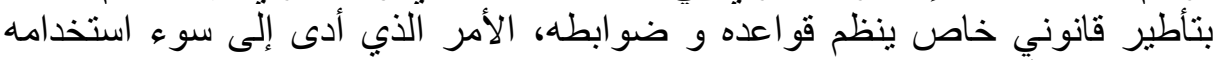

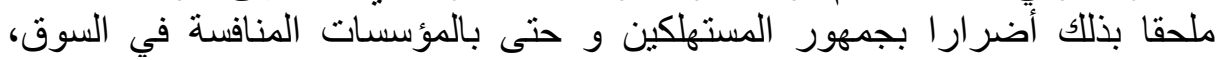

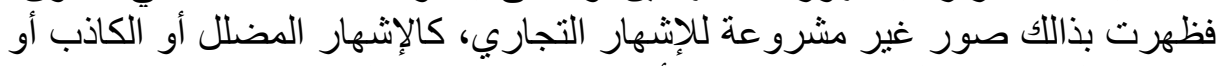

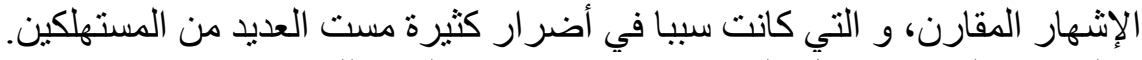

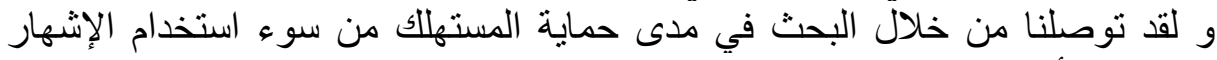

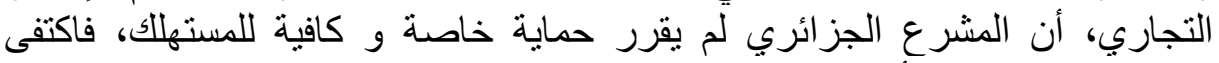

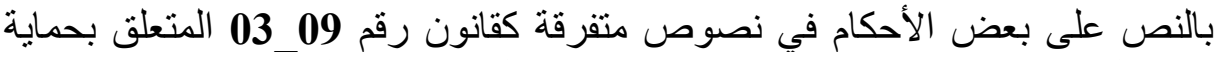

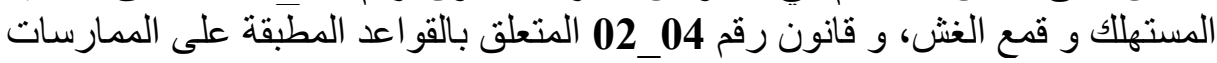

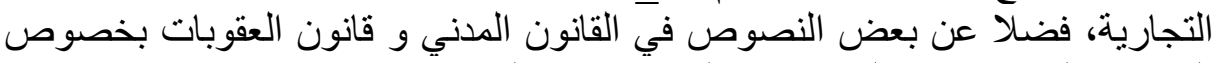

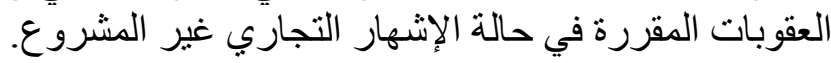

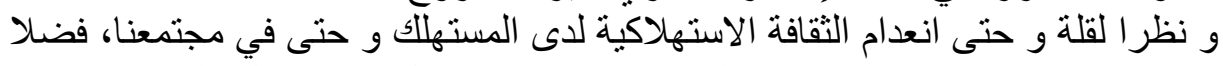

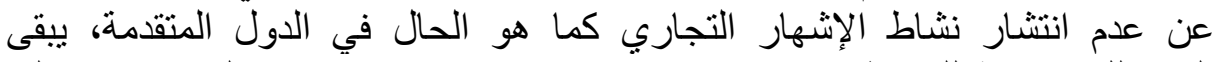
المستهلك عرضة للمخاطر و الإضرار بسبب سوء استخدام الإشهار التجاري، ولئ و عليه

نوصي بما يلي:

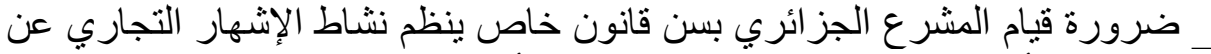

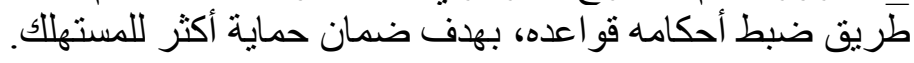

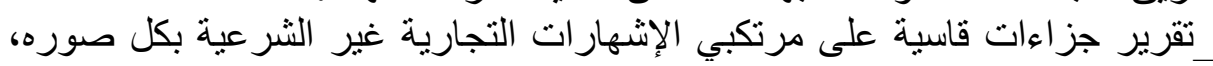
التتعدى العقوبات المالية و فرض عقى عربية بات سالبة للحرية.

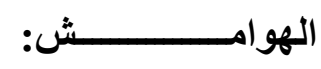

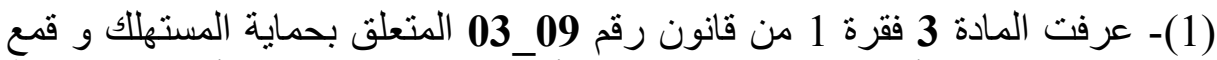

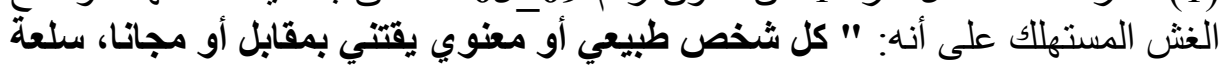

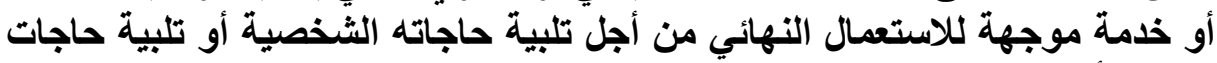

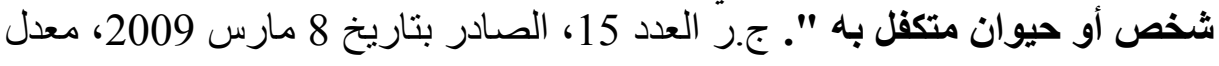

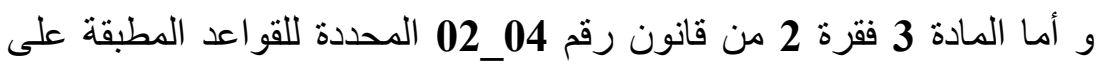

متمح.

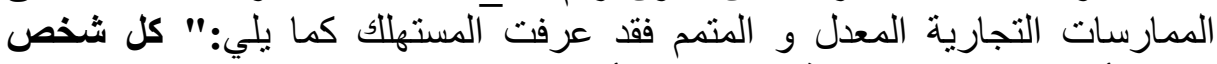

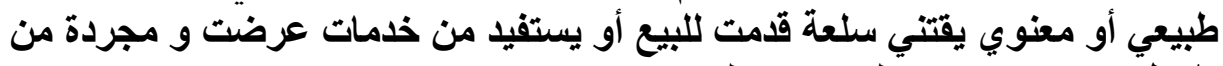

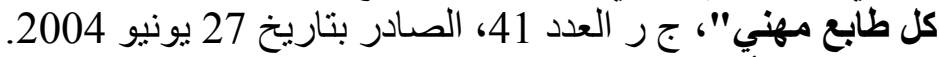

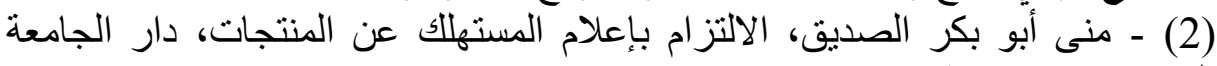

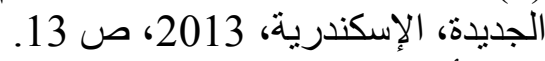
(3)- أما تعريف المشرع الفرنسي للإنشهار التجاري فلقد ورد في نص المادة 3 من

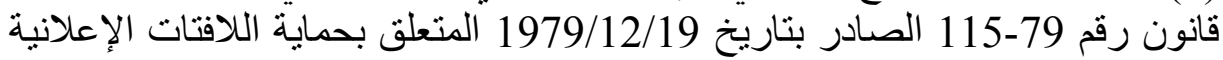
المعلقة على الجدر ان: راجع في ذلك:

HOUTCIEFF(Dimitri), droit commercial, Sirey, Paris, 2011, p.444.

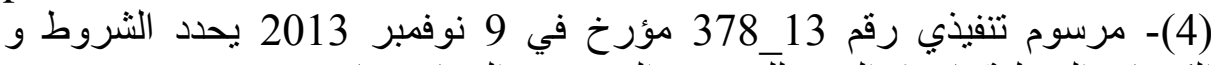

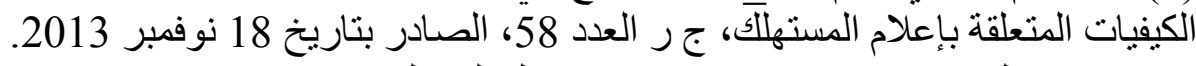

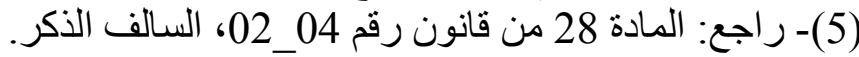

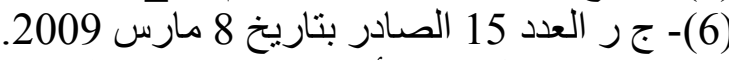

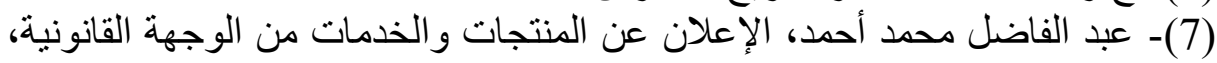

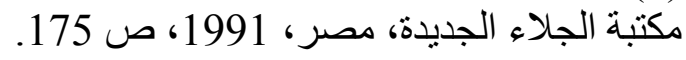


(8)- بتول صراوة عبادى، التظليل الإعلاني التجاري و أثره على المستهلك ، دار

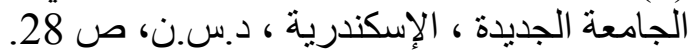

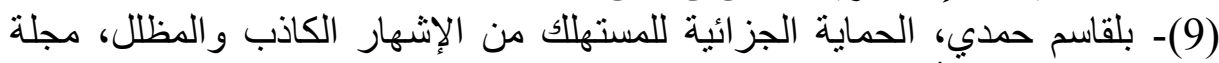

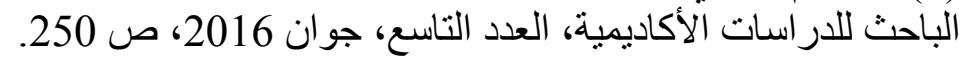

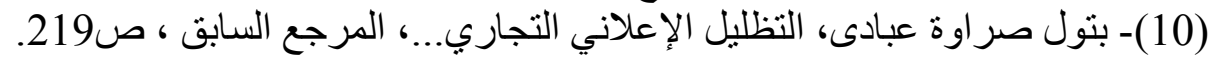

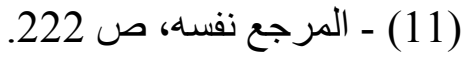
(12)- ممدوح خيري هشام، الحماية المدنية من الإعلانات التجارية الخادعة، دراسة

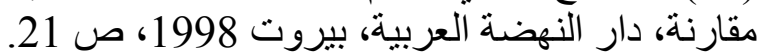
(13) - DAVIER(P.F), le mensonge en publicité, L.G.D.J, Paris, 1972 , p.20.

(14) - بلقاسم حمدي، الحماية الجز ائية للمستهلك من الإشهار ...، مرجع سابق، ص

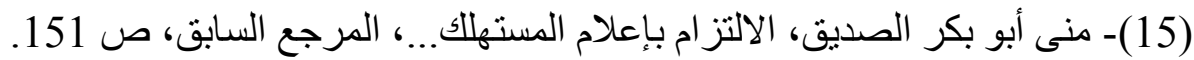

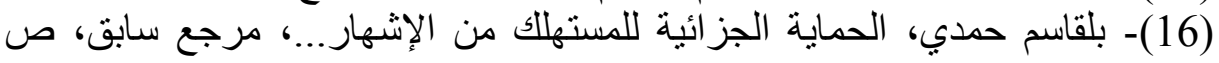

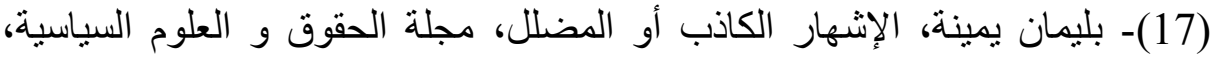

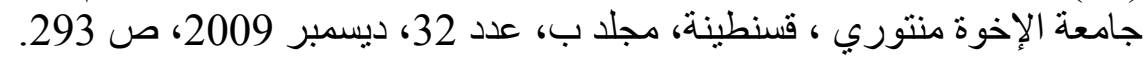

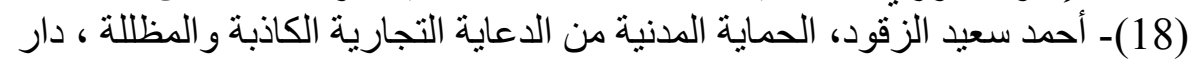

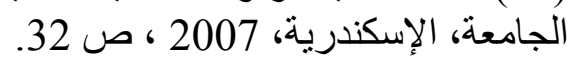

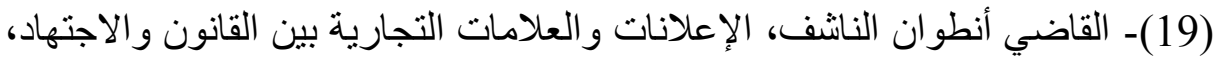

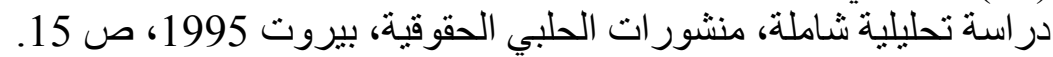

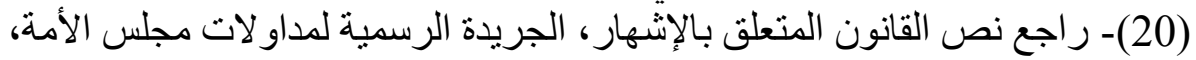

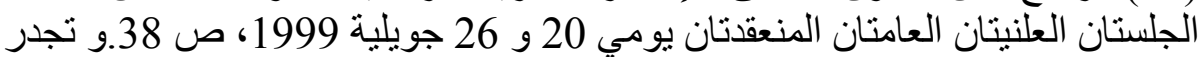

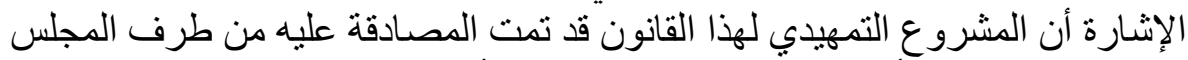

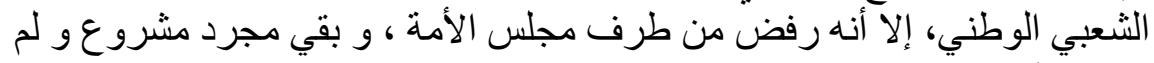

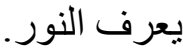

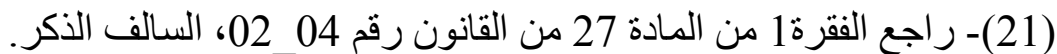

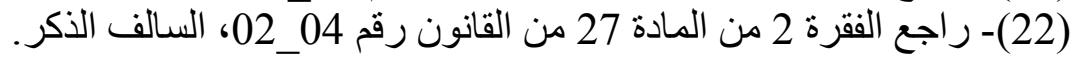

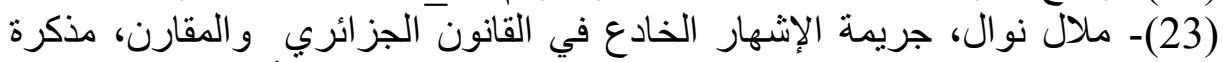

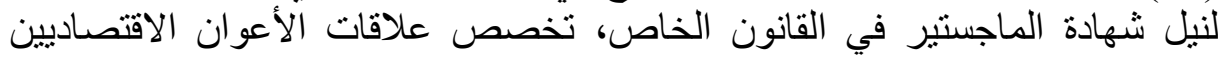
و المستهلكين، كلية الحقوق و العلوم السياسية، جامعة و هران ،

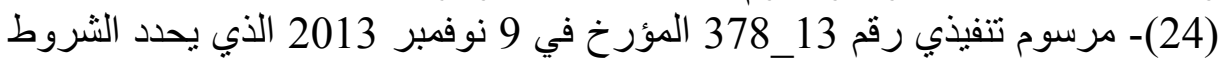

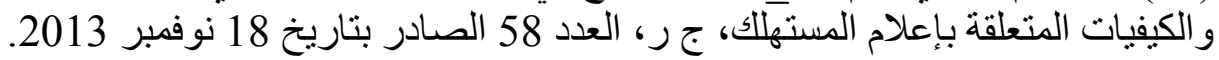
(25)- BOULOC (B), publicité, trompeuse, notion de publicité, RTD, com, 2006, p.1.

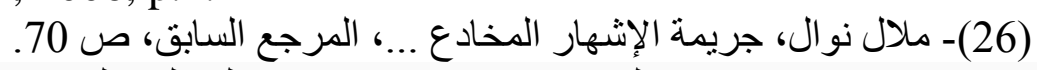

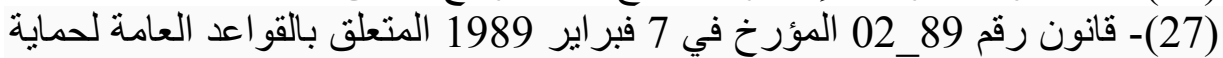

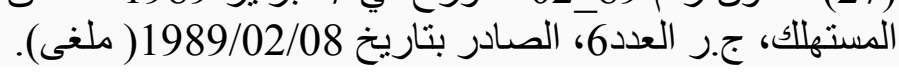

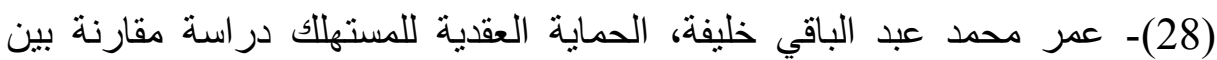

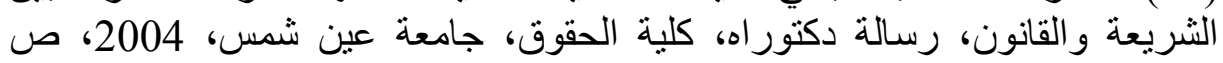

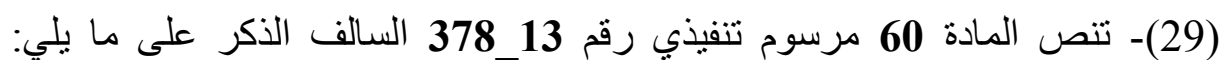
"يمنع استعمال أي بيان أو إثـارة أو تشمية خيالية أو كل طريقة تقديم أو وسم و كلّ مل 


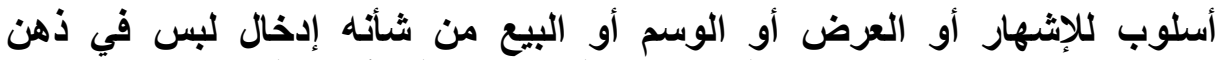

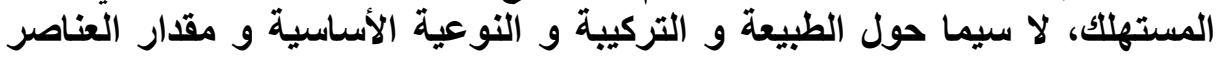

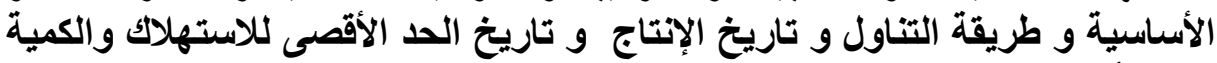
و منشأ و مصدر المنتوجة.... (30)- FABRE (Gérard) , concurrence, distribution ,édition Dalloz, Paris , 1983, p.62.

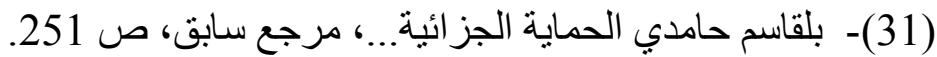

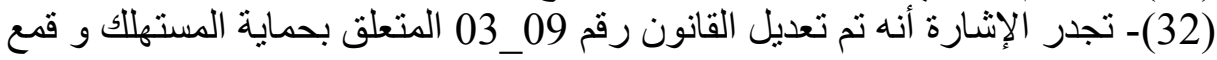

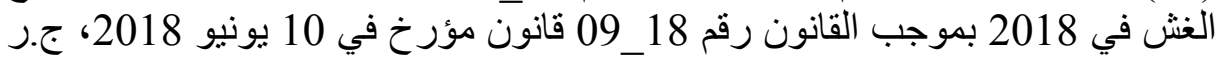
العدد 35، الصادر بتاريخ 13 يونيو

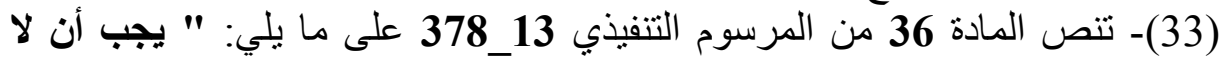

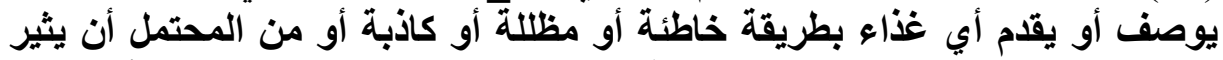

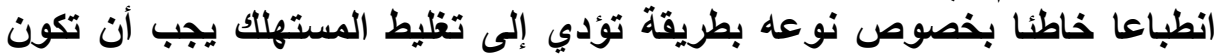

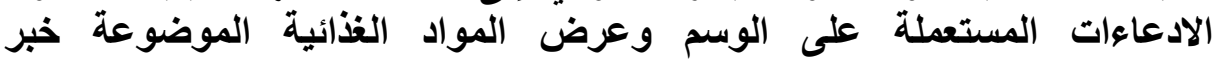

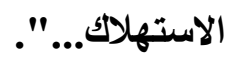

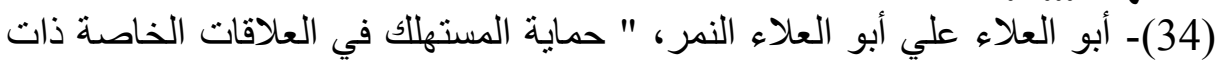

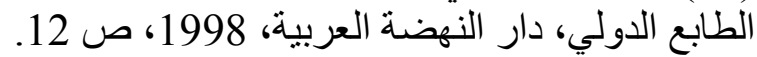

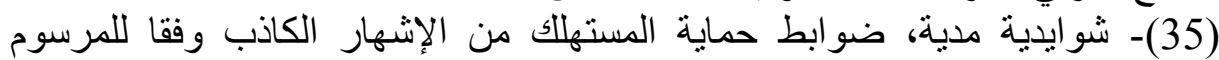

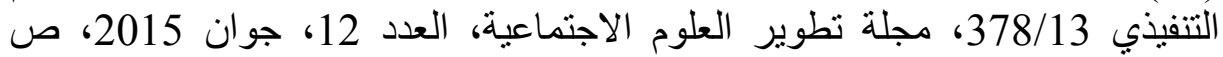

(36)- عبد الفتاح خذران، " دور أهمية الإثهار في المؤسسة الاقتصادية الخدمية،

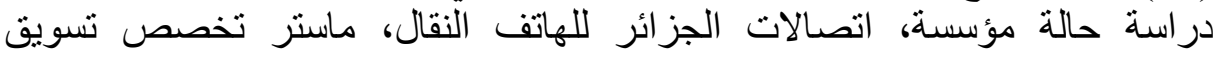

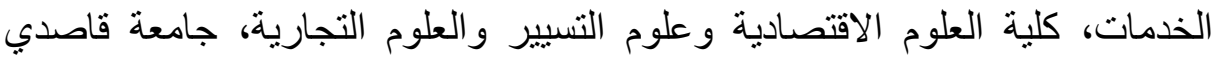

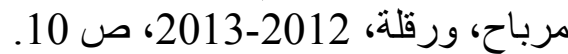

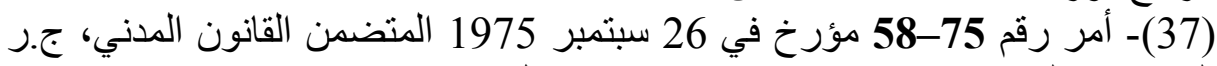

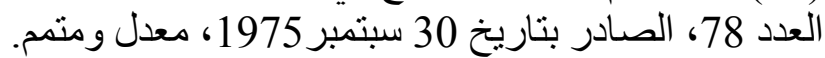

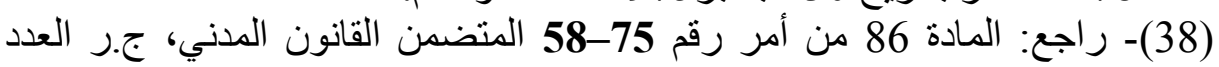

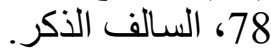

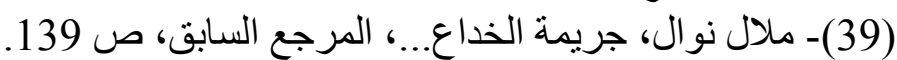

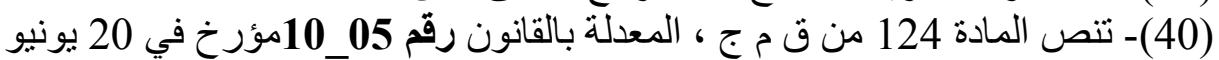

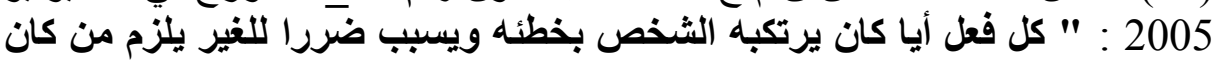
سببا في حدوثه بالتعويض".

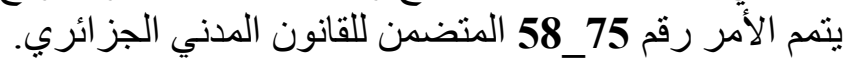

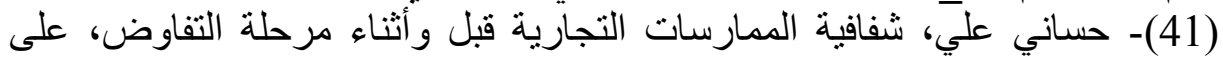
ضوء القانون رقم 04- 02 المؤرخ في 23 يونيو 2004، مجلة العارية العلوم القانونية الإدارية

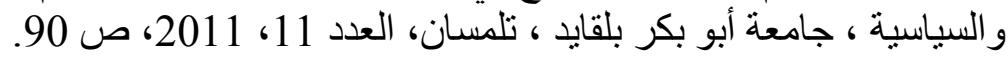

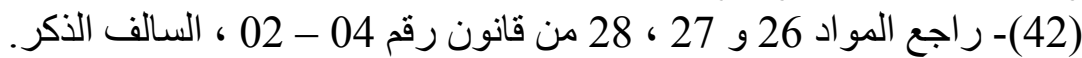

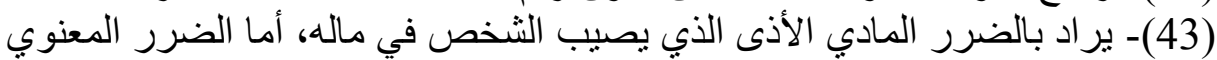
فهو الأذى الذي يصيب النثخ في شي شرفه و وعو اطفه.

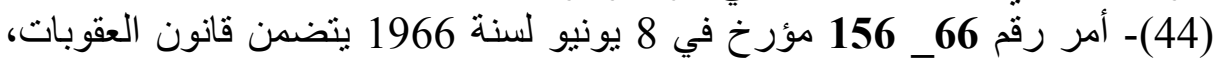

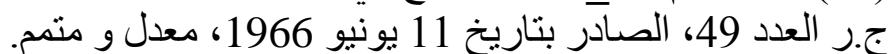

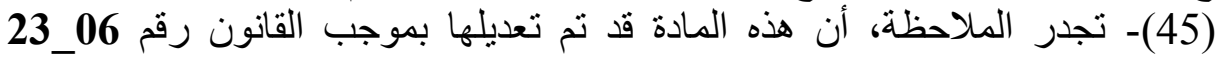

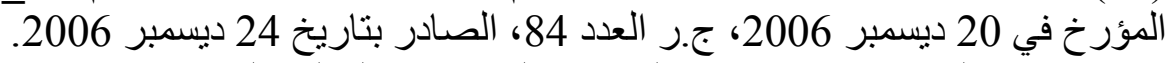
(46)- راجع المادة 430 من قانون العقوبات الجز ائري، السالف الذكر . 
(47)- راجع المادة 46 من القانون رقم 04 مـ201 المعدلة بموجب المادة 10 من القانون

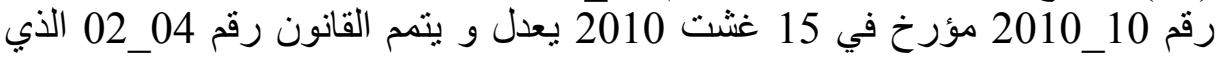

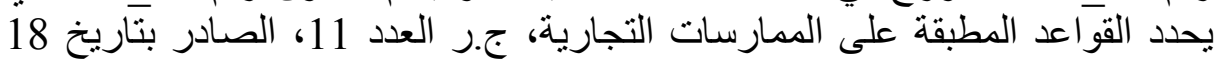
غشت 2018.

قائمة المراجع:

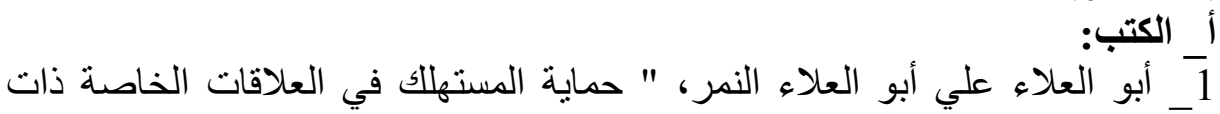

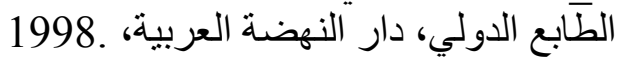

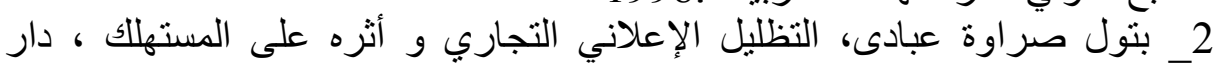
الجامعة الجديدة ، الإسكندرية ، د.س. د.ن. الإن. 3_ عبد الفاضل محمد أحمد، الإعلان عن الإنة المنتجات و الخدمات من الوجهة القانونية، مكتبة الجلاء الجديدة، مصر ، 1991 الجدي 4_ ممدوح خيري هشام، الحماية المدنية من الإعلانات التجارية الخادعة، دراسة مقارنة، دار النهضة العربية 1998 النيزية 5 منى أبو بكر الصديق، الالتزام بإعلام المستهلاك عن المنتجات، دار الجامعة الجديدة للنشر، الإسكندرية،

ب الرسائل و المذكرات الجامعية:

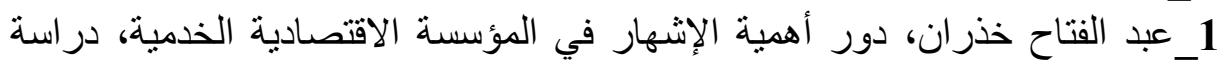

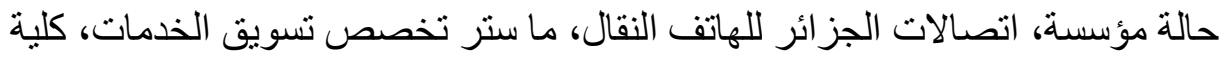
العلوم الاقتصادية وعلوم التسيير و العلوم التجارية، جامعة قاصدية ماتفي مرباح، ورقلة، 2013.-2012 2_عمر محمد عبد الباقي خليفة، الحماية العقدية للمستهلك در اسة مقارنة بين الثريعة والقانون، رسالة دكتور اه، كلية الحقوق، جامعة عين شمس، البعة 2004.

1 ج_بلقاسم حمدي، المقات العمية: الحماية الجزائية للمستهلك من الإشهار الكاذب و المظلل، مجلة

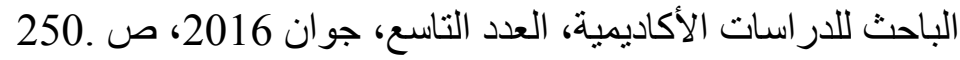

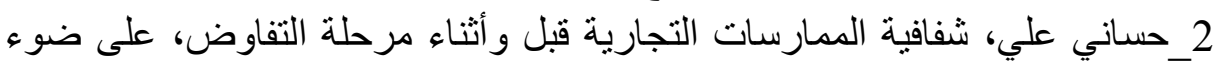
القانون رقم 04- 02 المؤرخ في 23 يونيو 2004، مجلة العبانة العلوم القانونية الإدارية

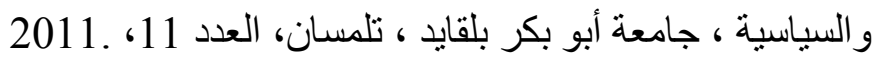

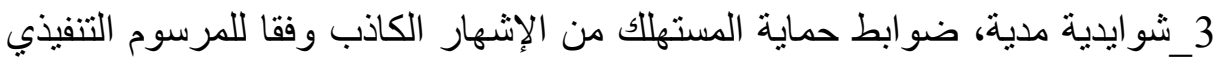

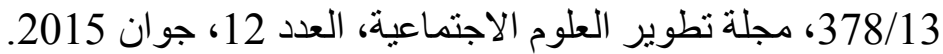

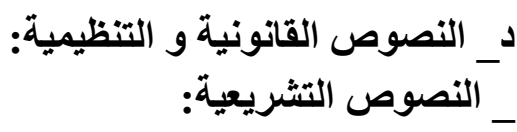
1__أمر رقم 66_ 156 مؤرخ في 8 يونيو لسنة 1966 يتضمن قانون العقوبات، ج.ر العدد 49، الصادر بتاريخ 11 يونيو 156 فورن 1966، معدل و منمح. 
2_ أمر رقم 75-58 مؤرخ في 26 سبتمبر 1975 المتضمن القانون المدني، ج.ر

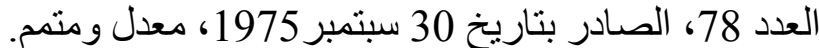

3_ قانون رقم 89_02 المؤرخ في 7 فبراير 1989 المتعلق بالقواعد العامة لحماية

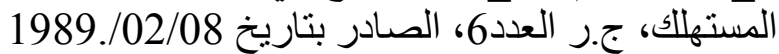

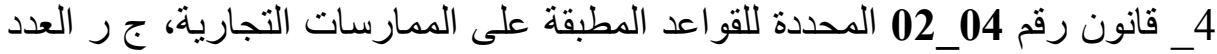

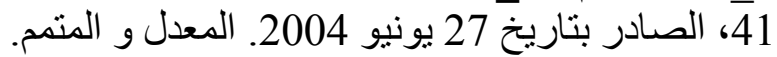

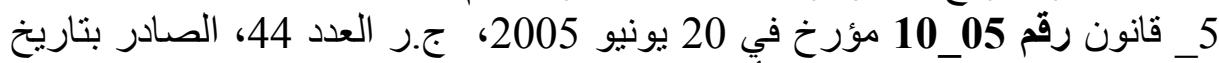

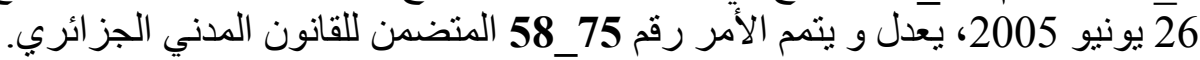

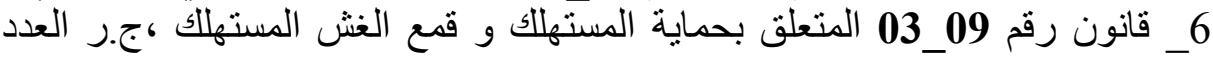

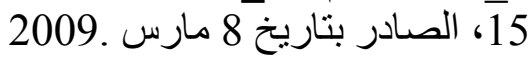

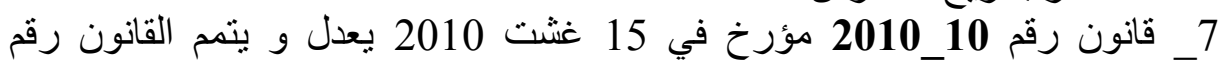

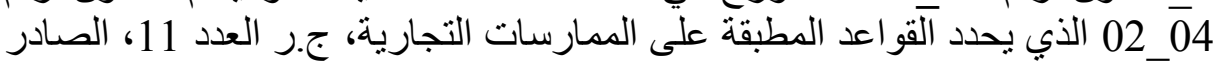

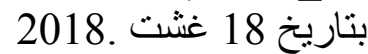

8_قانون رقم 18_09 قانون مؤرخ في 10 يونيو 2018، بعدل و يتمم القانونة

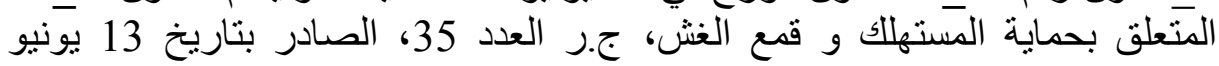

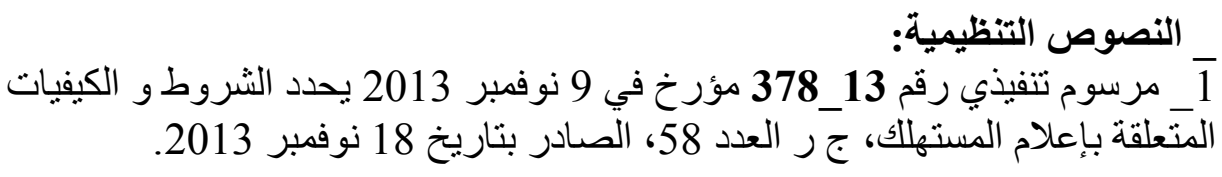

a_OUVRAGE :

_ باللغة (لفرنسية:

1_ FABRE (Gérard), concurrence, distribution, édition Dalloz, Paris, 1983.

2_DAVIER(P.F), le mensonge en publicité, L.G.D.J, Paris, 1972.

b_Article:

1_ BOULOC (B), publicité, trompeuse, notion de publicité, RTD, com, 2006. 